\title{
Analysis of Cutting Forces From Conventional to High-Speed Milling with Straight and Helical-Flute Tools for Flat-End Milling Incorporating the Effect of Tool Runout
}

Mehmet AYDIN ( $\nabla$ mehmet.aydin@bilecik.edu.tr)

Bilecik Şeyh Edebali University

Uğur Köklü

Karamanoğlu Mehmetbey University,

\section{Research Article}

Keywords: End milling, coefficients, forces, mechanistic model, tool geometry, runout

Posted Date: September 3rd, 2021

DOl: https://doi.org/10.21203/rs.3.rs-850919/v1

License: (a) (1) This work is licensed under a Creative Commons Attribution 4.0 International License.

Read Full License 


\title{
Analysis of cutting forces from conventional to high-speed milling with straight and helical-flute tools for flat-end milling incorporating the effect of tool runout
}

\author{
Mehmet Aydin (corresponding author) \\ Bilecik Şeyh Edebali University, \\ Department of Industrial Design, 11230 Bilecik, Turkey \\ Tel.: +902282141612 \\ Fax: +902282141282 \\ E-mail: mehmet.aydin@bilecik.edu.tr
}

Uğur Köklü

Karamanoğlu Mehmetbey University,

Department of Mechanical Engineering, 70100 Karaman, Turkey

\begin{abstract}
:
This paper presents a systematic study to analyze the dependence of cutting forces on tool geometry, workpiece material and cutting parameters such as spindle speed, tool engagement and cutting direction in flat-end milling with tool runout. The cutting forces are determined according to a mechanistic force model considering the trochoidal flute path to calculate the undeformed chip thickness, and average cutting force and linear regression model are applied for identifying the coefficients of the force model. A series of milling processes are conducted on AZ31 Magnesium $(\mathrm{Mg})$ alloy and titanium alloy (Ti6Al4V) to analyze the instantaneous cutting force curves, amplitudes of cutting forces and peak forces over a wide range of spindle speeds from conventional to high-speed milling. It is demonstrated that the values of the cutting force coefficients are higher at conventional spindle speed and decrease with an increase in spindle speed, especially when machining Ti6Al4V alloy. For the edge force coefficients, it is observed a slight variation when using cutting tools with different helix angles. Besides, the cutting force amplitudes strongly depend upon the workpiece material. The helix angle has a significant influence on the transverse force amplitude at conventional speed. The forces obtained mechanistically are also substantiated by comparison with measurements.
\end{abstract}

Keywords: End milling, coefficients, forces, mechanistic model, tool geometry, runout 


\section{Introduction}

End milling is one of the extensively utilized complex manufacturing methods in metalworking industries. Tool runout occurs from several sources such as tool axis offset, tool axis tilt and setting of inserts in end milling operations, which affects the instantaneous undeformed chip thickness and cutting forces depending on the cutting conditions and cutting geometry [1]. A large number of predictive cutting force models have been developed to examine the milling process, which focus on physical aspects. However, some fundamental physical phenomena are still difficult to understand in a wider range of cutting conditions. Thus, it seems interesting to analyze the physical phenomena with the help of cutting force modeling in many conditions.

Modeling of cutting forces in end milling constitutes the basis for predicting process stability [2], identifying surface location errors [3] and analyzing surface generation [4]. There are three different approaches to predict cutting forces in milling processes: analytical, numerical and mechanistic [5], where the situations of tool runout are considered. The analytical models relate cutting forces to process variables and mechanical aspects. Amarego and Deshpande proposed a force model using oblique cutting analyses [6]. In this model, they discussed the effects of deflection and tool eccentricity. Li et al. [7] developed another model including the effects of runout to predict milling forces applying Oxley's machining theory. In their model, the action of an individual flute segment was described as oblique cutting. Wang and Liang [8] proposed an analytical formulation to compute the chip load in milling processes with the effect of runout. In this formulation, the cutting geometry was modelled based on the circular flute trajectory. While this approximation greatly simplifies the analysis, it causes significant errors. Advances in computers have led to the development of numerical methods, where the relationship between tool geometry and workpiece is studied with the finite element-based models [9].

In mechanistic model, cutting forces are proportional to undeformed chip area [10]. Kline et al. [11] presented a mechanistic model to predict milling forces for the cutting geometry with tool runout. They calibrated the empirical coefficients with the measured average forces and an undeformed chip thickness approach, which are referred to as force coefficients. Based on a similar mechanistic cutting force model considering the runout and tool deflection, Yun and Chu [12] determined the cutting forces for flat-end milling. A general approach was established by Wan and Zhang [13] for cutting force prediction in milling operations, who included the influences of the tool and workpiece and immersion angle variation. Montgomery and Altintas [14] proposed a theoretical cutting force method which describes the undeformed chip thickness considering trochoidal motion of the tool. Recently, Wojciechowski [15] investigated cutting forces in ball-end milling of inclined surfaces by including the effect of surface inclination and tool runout. However, in die and mold making operations, where cutting conditions change, a variety of cut tests are necessary to determine the cutting forces. Considering the cutting tool, workpiece and cutting parameters, a systematic investigation of the influences of tool runout on the milling process based upon trochoidal flute trajectories should be performed.

There are mainly two approaches for identifying the force coefficients, i.e., mechanistic approach [16-18], oblique transformation method [19-21]. These 
approaches require a linear regression of the measured cutting forces over a range of feed rates using a constant cutting speed and depth of cut. Another method [22] employs a nonlinear optimization approach to carry out a least-squares fitting of predicted cutting forces to measured ones, which allows to study the effects of machining parameters on dynamic cutting forces. By decomposing the cutting forces into nominal and perturbation components, Wan et al. [23, 24] also suggested an approach which calibrates simultaneously the force coefficients and tool runout by solving nonlinear equations for flat-end milling.

This paper presents a systematic study to determine the cutting forces for flat-end milling process with tool runout by considering the effects of tool geometry, workpiece material and cutting parameters such as spindle speed, tool engagement and cutting direction. Numerous milling processes are also conducted to accurately determine the instantaneous cutting force curves, amplitudes of cutting forces and peak forces over a wide range of spindle speeds from conventional to high-speed machining. A mechanistic force model which determines the cutting forces based on the undeformed chip thickness calculated from the trochoidal flute path is used, and the force coefficients are derived using average cutting force and linear regression model.

\section{Mechanistic cutting force model}

An end milling with a straight-flute end mill is depicted in Fig. 1. The motion of cutting edge is a combination of rotation and translation. The orientation and magnitude of cutting forces change because this relative motion causes a chip geometry that varies with time. Thus, it is required to consider the trajectory of cutting edges to determine forces accurately.

To model the cutting forces for straight end milling, a mechanistic force model is applied, which is proven in the literature $[25,26]$. This model relates the cutting force components to the undeformed chip thickness. Tangential $\left(F_{t}\right)$ and radial $\left(F_{r}\right)$ forces applied on the $k$ th flute of a rigid end mill at time $t$ are described by

$$
\left.\begin{array}{l}
F_{t}^{k}(t)=\left(K_{t c} w_{k}(t)+K_{t e}\right) d_{a} \\
F_{r}^{k}(t)=\left(K_{r c} w_{k}(t)+K_{r e}\right) d_{a}
\end{array}\right\}
$$

where $K_{t c}$ and $K_{r c}$ denotes the tangential and radial cutting force coefficients, respectively. $K_{t e}$ and $K_{r e}$ are the corresponding edge force coefficients. $d_{a}$ is the axial depth and $w_{k}(t)$ is the undeformed chip thickness.

The tangential and radial forces are then resolved into feed $\left(F_{x}\right)$ and transverse $\left(F_{y}\right)$ force components as

$$
\left\{\begin{array}{l}
F_{x}^{k}(t) \\
F_{y}^{k}(t)
\end{array}\right\}=\left[\begin{array}{cc}
\cos \theta_{k}(t) & \sin \theta_{k}(t) \\
\sin \theta_{k}(t) & -\cos \theta_{k}(t)
\end{array}\right]\left\{\begin{array}{c}
F_{t}^{k}(t) \\
F_{r}^{k}(t)
\end{array}\right\}
$$

where $\theta_{k}(t)$ is the rotation angle of the $k$ th flute.

The contributions of entire flutes are computed, and added to achieve the total instantaneous forces on the tool at the current time as follows 
$F_{q}(t)=\sum_{k=1}^{N_{f}} F_{q}^{k}(t) \quad(q=x, y)$

where $N_{f}$ is the flute number.

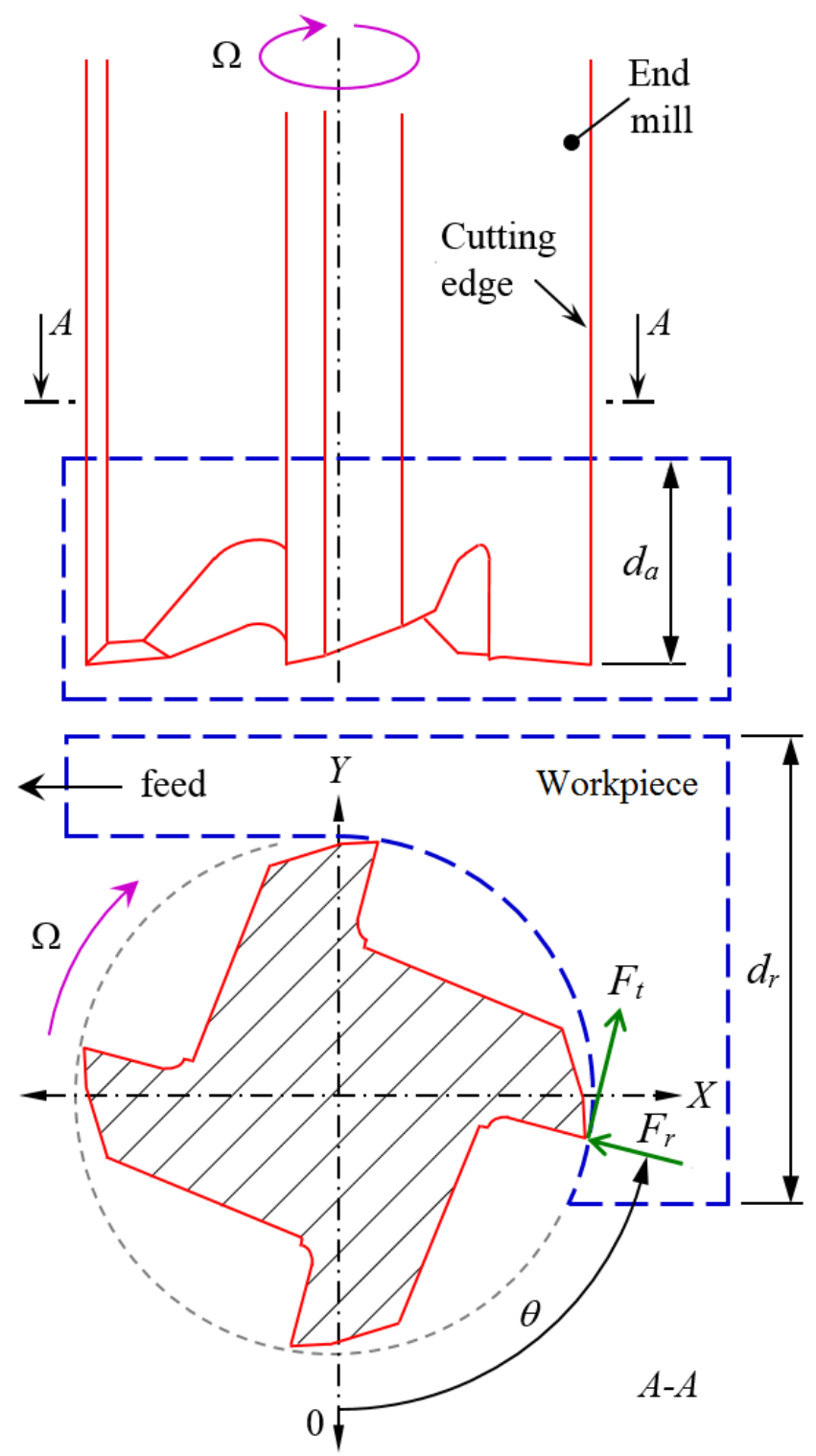

Fig. 1 Straight-flute end milling

To account for the effect of helix angle $(\beta)$, the end mill is discretized into $L$ number of disk elements along its axis, whose elementary length is $d z=d_{a} / L$, as illustrated in Fig. 2. Considering the $i$ th disk of the $k$ th flute at the $j t$ h angular position of the tool, the immersion angle is expressed as

$\theta_{k}(t)=\phi(j)+(k-1) \theta_{c}+\psi(i)$

where $\phi(j)=\alpha+j d \phi$ is the position angle of flute tip, and is calculated with respect to the initial position angle $(\alpha)$ by indexing the amount of angular increment $(d \phi) . \theta_{c}=2 \pi / N_{f}$ is the pitch angle. The lag angle $(\psi(i))$ is calculated using

$\psi(i)=i d z[\tan (\beta / r)]$

where $r$ is the tool radius. 


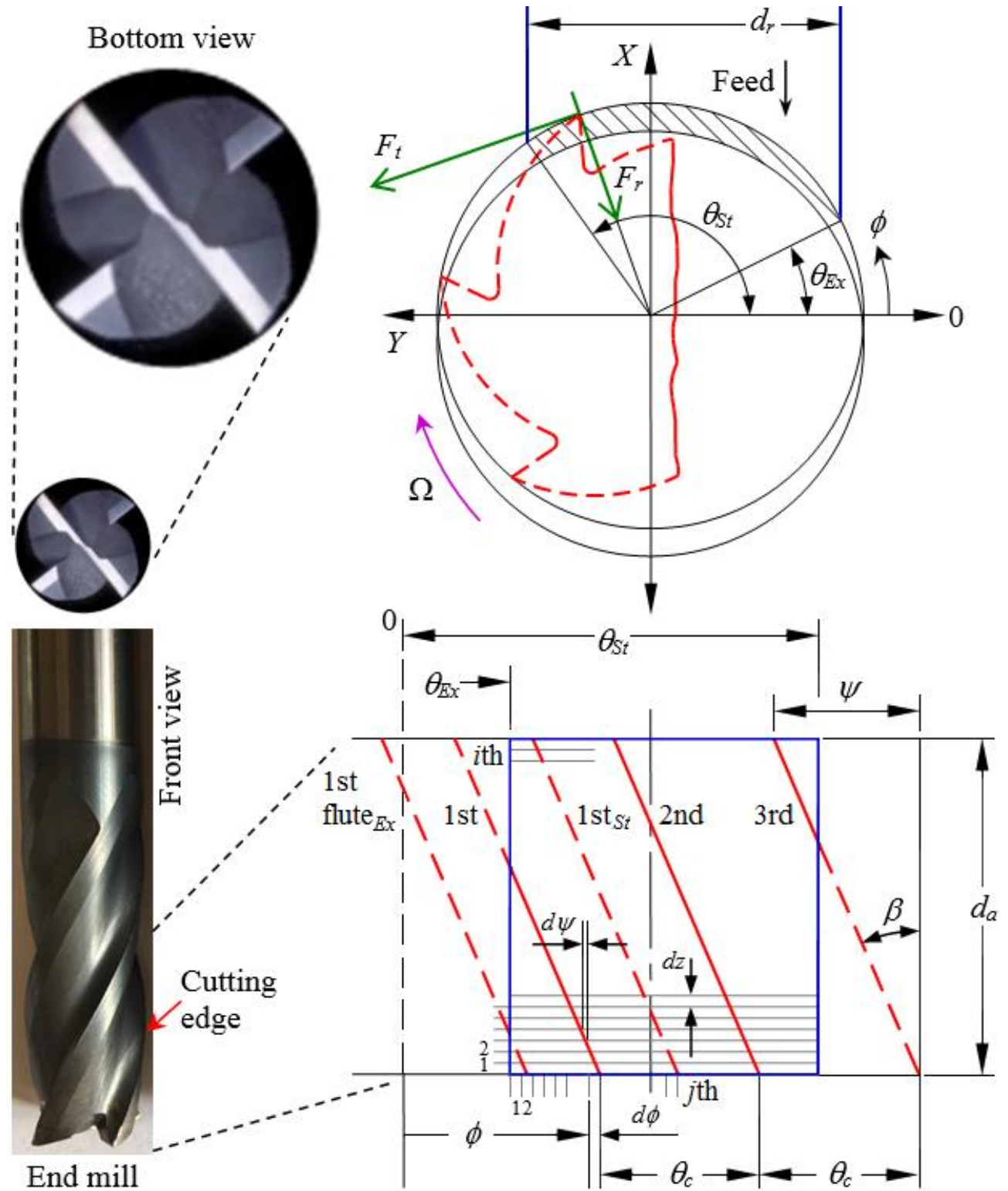

Fig. 2 Helical-flute end milling [27]

In helical end milling, the elemental tangential $\left(d F_{t}\right)$ and radial $\left(d F_{r}\right)$ forces are defined as

$$
\begin{aligned}
& d F_{t}^{k}(t)=\left(K_{t c} w_{k}(t)+K_{t e}\right) d z \\
& d F_{r}^{k}(t)=\left(K_{r c} w_{k}(t)+K_{r e}\right) d z
\end{aligned}
$$

Subsequently, the elemental forces are expressed in the Cartesian coordinate system as given below

$$
\left\{\begin{array}{l}
d F_{x}^{k}(t) \\
d F_{y}^{k}(t)
\end{array}\right\}=\left[\begin{array}{cc}
\cos \theta_{k}(t) & \sin \theta_{k}(t) \\
\sin \theta_{k}(t) & -\cos \theta_{k}(t)
\end{array}\right]\left\{\begin{array}{l}
d F_{t}^{k}(t) \\
d F_{r}^{k}(t)
\end{array}\right\}
$$

The total forces applied on the $k$ th flute at time $t$ are evaluated by integrating Eq. (7) along the axial depth

$$
F_{q}^{k}(t)=\int_{0}^{z} d F_{q}^{k}(t) d z \quad(q=x, y)
$$


where $z$ is the axial coordinate of the $i$ th disk of the $k$ th flute.

Finally, the total instantaneous forces at the current time are calculated by summing the forces generated by all flutes.

The flowchart for determining the cutting forces in helical end milling simulation is illustrated in Fig. 3. The simulation begins by defining the cutting parameters (spindle speed $(\Omega)$, axial depth $\left(d_{a}\right)$, feed rate $(f)$, entry and exit angles $\left(\theta_{S t}, \theta_{E x}\right)$, tool radius $(r)$, number of flutes $\left(N_{f}\right)$, force coefficients etc.) and numerical parameters (initial time and angle values, numbers of time steps $(T)$, angular steps $(K)$ and axial steps $(L)$, time interval $(d t)$, integration angle $(d \phi)$ etc.). Then, the program runs the time loop for discretized disks. The program checks for each time interval $(d t)$ whether the angular position of $k$ th flute of the $i$ th disk is in cut or out of cut. If cutting edge is not in cut, the forces are adjusted to zero. Otherwise, the forces in feed and transverse directions $\left(F_{x}, F_{y}\right)$ are evaluated using Eq. (7). The main loop continuous until the number of simulated time steps equals the predefined one. At the final stage, the program plots the forces.

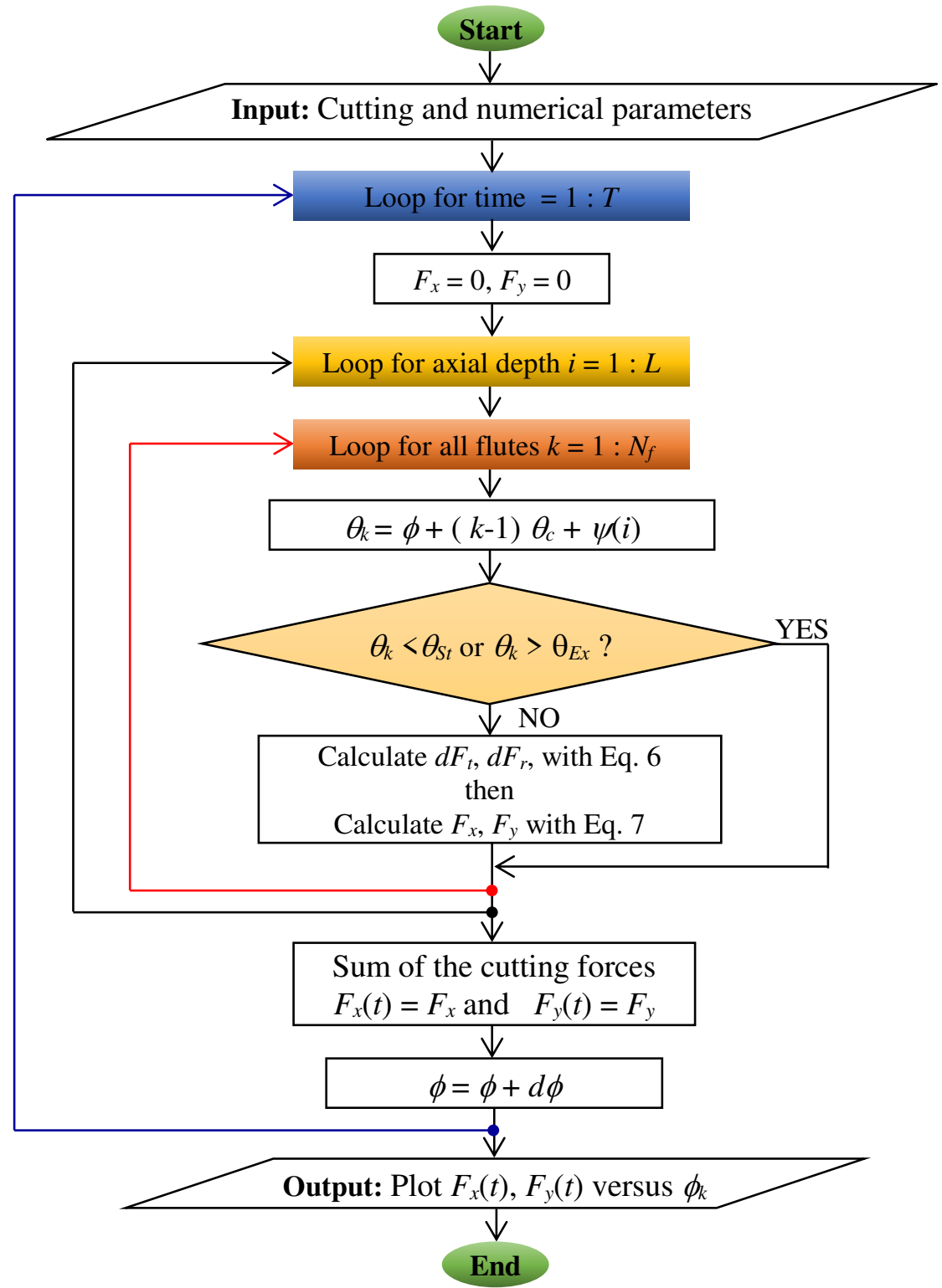

Fig. 3 Flowchart for calculating cutting forces in helical end milling 


\section{Calibration of force model coefficients}

It is necessary to calibrate the force model coefficients to make cutting force predictions. There are various methods to calibrate the model coefficients. Here, the force coefficients were derived from the average force components measured during slot cutting experiments which were conducted over a range of feeds per tooth $\left(f_{z}\right)$ with a constant spindle speed and axial depth. Such a method was also used by Dikshit et al. [28]. A single-flute end mill was used to eliminate the effects of runout. Projecting the tangential and radial force components into the Cartesian coordinate system and integrating over one revolution yield the following expressions for average cutting forces in feed $(X)$ and transverse $(Y)$ directions [22].

$$
\begin{aligned}
\bar{F}_{x}= & \frac{N_{f} d_{a}}{8 \pi}\left\{K_{t c}\left[\cos 2 \theta_{S t}-\cos 2 \theta_{E x}\right]+K_{r c}\left[\left(2 \theta_{E x}-\sin 2 \theta_{E x}\right)\right.\right. \\
& \left.\left.-\left(2 \theta_{S t}-\sin 2 \theta_{S t}\right)\right]\right\} f_{z}+\frac{N_{f} d_{a}}{2 \pi}\left\{K_{t e}\left[\sin \theta_{E x}-\sin \theta_{S t}\right]\right. \\
& \left.+K_{r e}\left[\cos \theta_{S t}-\cos \theta_{E x}\right]\right\} \\
\bar{F}_{y}= & \frac{N_{f} d_{a}}{8 \pi}\left\{K_{t c}\left[\left(2 \theta_{E x}-\sin 2 \theta_{E x}\right)-\left(2 \theta_{S t}-\sin 2 \theta_{S t}\right)\right]+K_{r c}\left[\cos 2 \theta_{E x}\right.\right. \\
& \left.\left.-\cos 2 \theta_{S t}\right]\right\} f_{z}+\frac{N_{f} d_{a}}{2 \pi}\left\{K_{t e}\left[\cos \theta_{S t}-\cos \theta_{E x}\right]\right. \\
& \left.+K_{r e}\left[\sin \theta_{S t}-\sin \theta_{E x}\right]\right\}
\end{aligned}
$$

where $\theta_{S t}$ and $\theta_{E x}$ represent the entry and exit angles, respectively. Eqs. (9) and (10) can be arranged in matrix form as

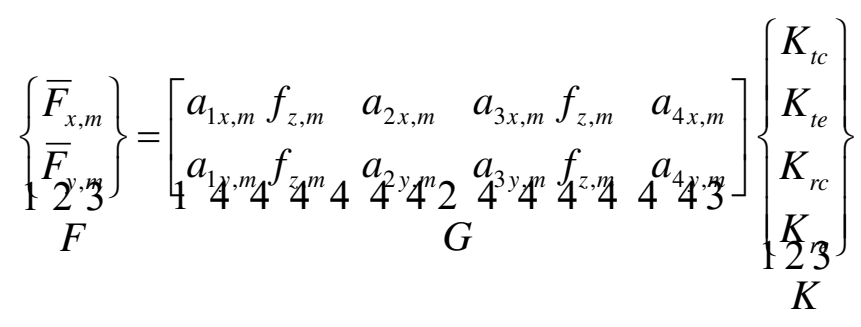

where $F$ and $K$ are the force and coefficient vectors, respectively. $G$ is the geometry matrix which is related to the cutting geometry. The subscript $m$ represents the number of cutting conditions for the calibration. In this study, calibration was performed using four different feed rates. Thus, the sizes of the $F$ vector, $G$ matrix and $K$ vector are $8 \times 1,8 \times 4$ and $4 \times 1$, respectively.

The elements of the geometry matrix are given in the equations below. For feed direction, the matrix elements are defined as

$$
\begin{aligned}
& a_{1 x}=\frac{N_{f} d_{a}}{8 \pi}\left[\cos 2 \theta_{S t}-\cos 2 \theta_{E x}\right] \\
& a_{2 x}=\frac{N_{f} d_{a}}{2 \pi}\left[\sin \theta_{E x}-\sin \theta_{S t}\right] \\
& a_{3 x}=\frac{N_{f} d_{a}}{8 \pi}\left[\left(2 \theta_{E x}-2 \theta_{S t}\right)+\left(\sin 2 \theta_{S t}-\sin 2 \theta_{E x}\right)\right]
\end{aligned}
$$


$a_{4 x}=\frac{N_{f} d_{a}}{2 \pi}\left[\cos \theta_{S t}-\cos \theta_{E x}\right]$

For transverse direction, the matrix elements are defined as

$$
\begin{aligned}
& a_{1 y}=\frac{N_{f} d_{a}}{8 \pi}\left[\left(2 \theta_{E x}-2 \theta_{S t}\right)+\left(\sin 2 \theta_{S t}-\sin 2 \theta_{E x}\right)\right] \\
& a_{2 y}=\frac{N_{f} d_{a}}{2 \pi}\left[\cos \theta_{S t}-\cos \theta_{E x}\right] \\
& a_{3 y}=\frac{N_{f} d_{a}}{8 \pi}\left[\cos 2 \theta_{E x}-\cos 2 \theta_{S t}\right] \\
& a_{4 y}=\frac{N_{f} d_{a}}{2 \pi}\left[\sin \theta_{S t}-\sin \theta_{E x}\right]
\end{aligned}
$$

Applying least-squares fitting method to the force vector and geometry matrix, the coefficients are calibrated as follows

$$
K=\left[G^{T} G\right]^{-1} G^{T} F
$$

\section{Instantaneous chip thickness model}

There are two types of tool runout, radial and axial. The axial runout, whose influence on the cutting forces is disregarded, is very small compared to the axial depth. However, the radial runout has the same order as feed per tooth [7]. Therefore, the analysis is focused on radial runout, which is described as the offset of tool from the axis of rotation.

The trajectories of cutting edges with respect to the workpiece in milling are trochoidal [29], as illustrated in Fig. 4a. The undeformed chip thickness can be modeled by considering flute trajectories incorporating tool runout [30].

The trajectory of the cutting point at the tip of the $k$ th flute is given as

$$
\begin{aligned}
& x_{k}=r \sin \left(\theta_{k}(t)\right)+x_{C} \\
& y_{k}=r \cos \left(\theta_{k}(t)\right)+y_{C}
\end{aligned}
$$

The position of the tool center in the coordinate system $X O Y$ can also be described as follows

$$
\begin{aligned}
& x_{C}=\rho \sin (\lambda+\phi(j))+f t \\
& y_{C}=\rho \cos (\lambda+\phi(j))
\end{aligned}
$$

where $x_{C}$ and $y_{C}$ are the coordinates of tool center in feed and transverse directions, respectively. $f$ is the feed rate. $t$ is the time. $\rho$ is the runout offset, and $\lambda$ is the location angle. The trochoidal motion, which occurs in feed direction, is accounted for through the expression $f t$.

The undeformed chip thickness is the length between two consecutive workpiece surfaces as illustrated in Fig. 4b. Assuming that the $k$ th flute removes the surface generated by a previously passing one. The line $P C$ intersects the path curve left by the tip of the previous flute at point $R$. When the tip of the previous flute is at point $R$, the coordinates of point $R\left(x_{R}, y_{R}\right)$ can be found from Eq. (21). At this moment, 
the center of tool is at point $C$, and its coordinates $\left(x_{C}, y_{C}\right)$ can be obtained using Eq. (22).

The length of the line segment $P R$ corresponds the instantaneous undeformed chip thickness $\left(w_{k}\right)$, and can be determined as follows

$$
\begin{aligned}
w_{k} & =P R=|P C|-|R C| \\
& =r-\sqrt{\left(x_{R}-x_{C}\right)^{2}+\left(y_{R}-y_{C}\right)^{2}}
\end{aligned}
$$
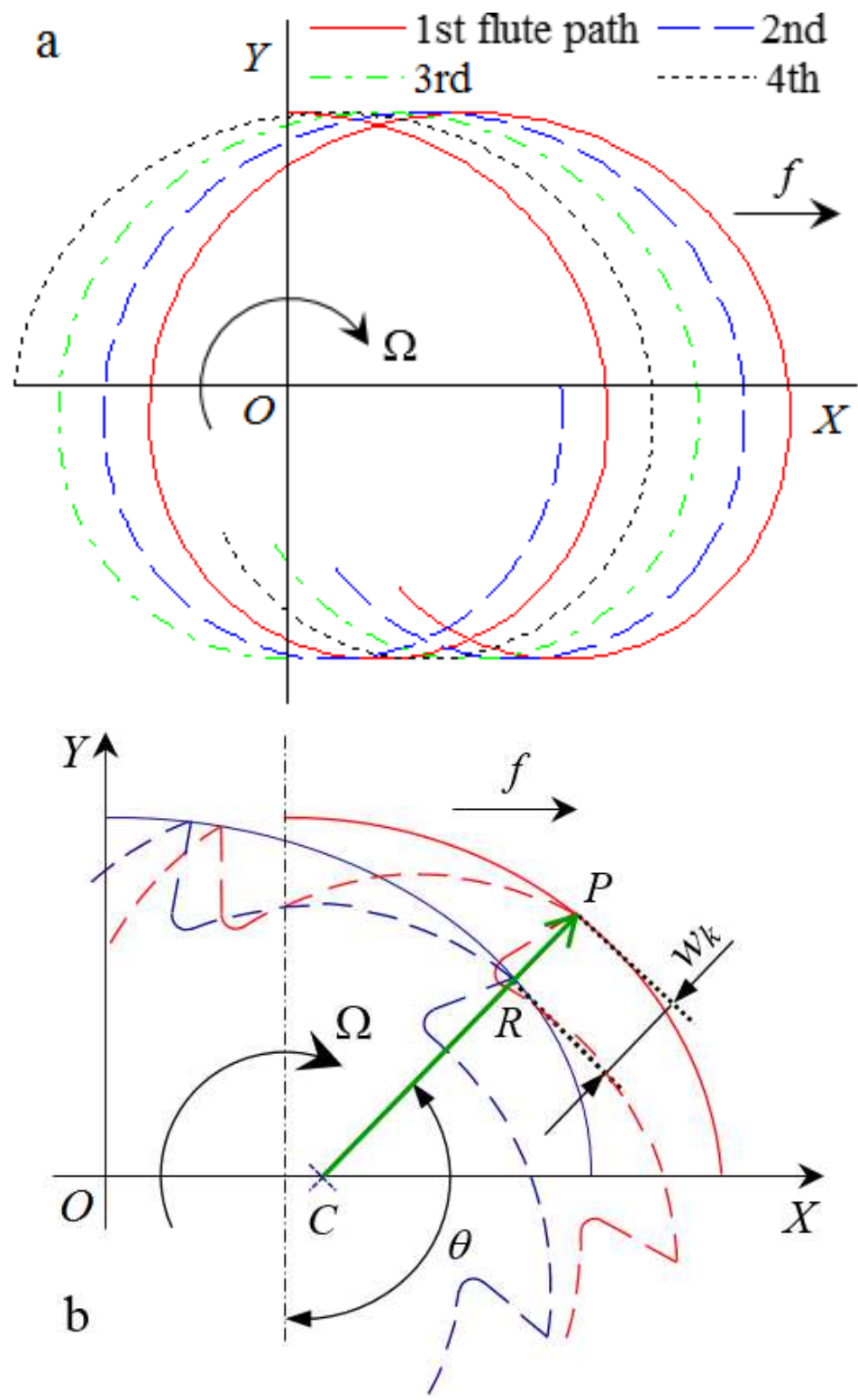

Fig. 4 Helical end milling with runout: (a) Trochoidal trajectory, (b) Chip thickness geometry

\section{Determination of runout parameters}

The radius of each flute can be measured when the end mill is attached to the spindle. Assuming that on an end mill with clockwise rotation, there are $N_{f}$ flutes labelled counterclockwise as No. 1, 2, .., $N_{f}$, and the flutes are uniformly 
distributed. The runout offset of the $k$ th flute is $e_{r k}$, where $k=1,2, \ldots, N_{f}$. As presented in Ref. [31], the actual radius of the $k$ th flute can be regarded as $r_{k}=r$ $+e_{r k}$. The runout perpendicular to the cutting edge is neglected as in Eq. (24). Fig. 5 shows the convention employed for runout.

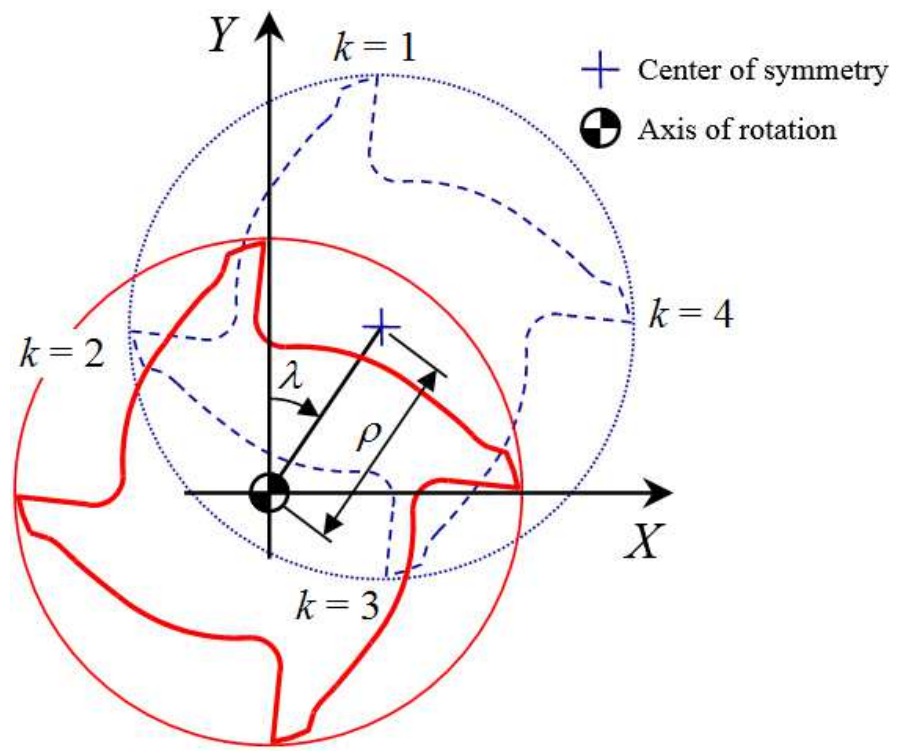

Fig. 5 Runout offset and location angle definitions

$r_{1}=\sqrt{(r+\rho \cos \lambda)^{2}+\underset{\text { negligible }}{\left(\rho_{4} \sin \lambda\right)^{2}}}=r+\rho \cos \lambda$

Thus, the edge radius equations for a four-flute end mill can be defined as

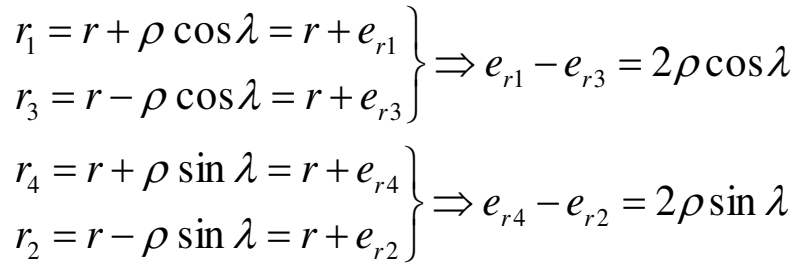

From the above equations, the runout offset and location angle can be found as

$\rho=\frac{\sqrt{\left(e_{r 1}-e_{r 3}\right)^{2}+\left(e_{r 4}-e_{r 2}\right)^{2}}}{2}, \lambda=\tan ^{-1}\left[\frac{e_{r 4}-e_{r 2}}{e_{r 1}-e_{r 3}}\right]$

It is noted that the location angle is set to its minimum positive equivalent $0 \leq \lambda<90^{\circ}$ for the four-flute end mill.

\section{Milling experiment procedure}

\subsection{Milling machine}

The entire milling experiments were performed on 3-axis Quaser MV154C vertical milling machine. This machine allows to cut materials at high spindle speeds. It has a maximum spindle speed of 10,000 rev/min. The machine table moves in feed and transverse directions, and the spindle moves vertically on the column. 


\subsection{Experimental setup}

The cutting forces were measured by using a dynamometer (Kistler 9257B) which was fixed on the machine table. The dynamometer was connected to the computer through a charge amplifier (Kistler 5070) and National Instruments data acquisition card. Post-processing of data was treated through DynoWare software. Before the cutting experiments, the tool runout was adjusted by placing a thin aluminum alloy film with the end mill in the tool chuck. Then, the radii of all flutes at the free ends of the end mills were measured through a dial indicator with a precision of 0.001 $\mathrm{mm}$ to quantify the runout values for each cutting tool. To minimize the influence of runout measurement deviations, each measurement was repeated two times to establish a statistical mean. Table 1 lists the calculated runout parameters for each tool. Fig. 6 shows the experimental setups for cutting force and tool runout measurements.
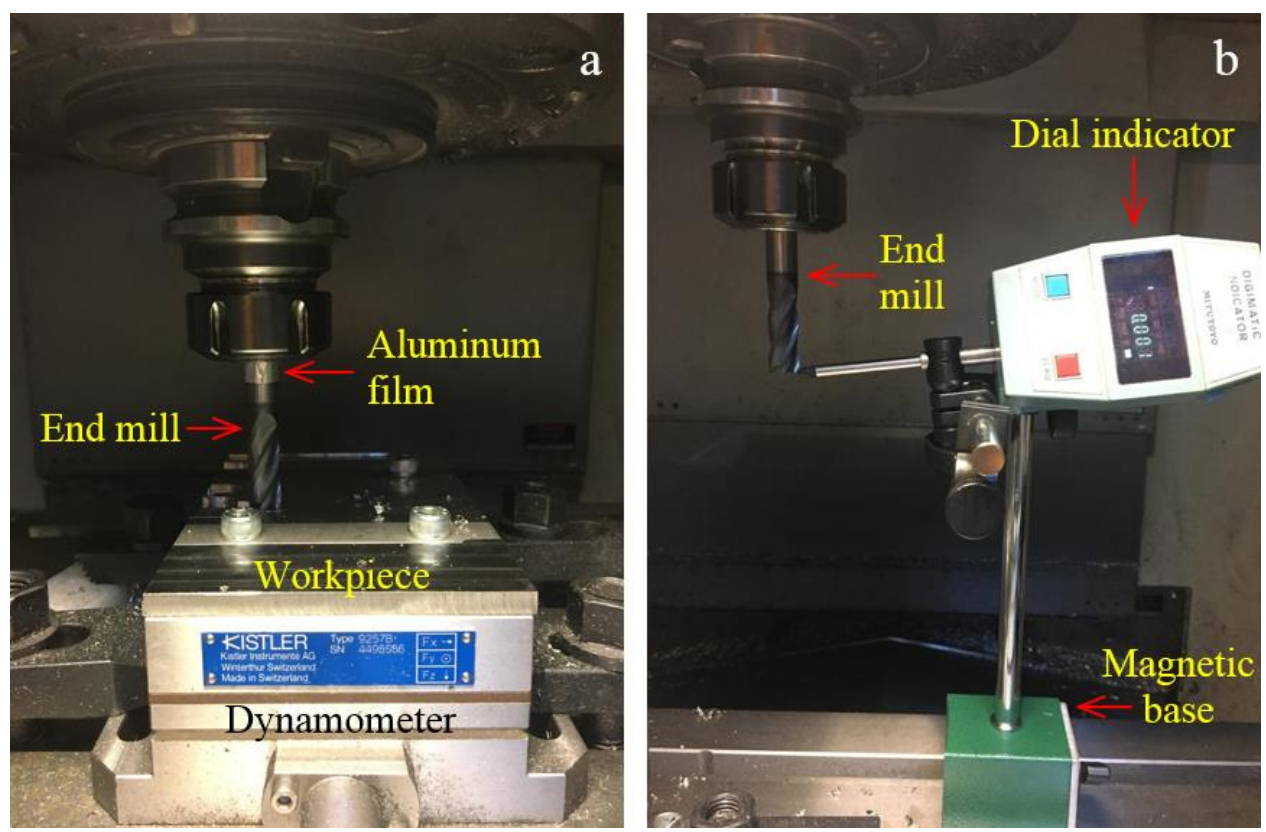

Fig. 6 Experimental setups: (a) Cutting force measurement, (b) Runout measurement

Table 1 Runout parameters

\begin{tabular}{ccc}
\hline Tool & Runout offset, $\rho(\mathrm{mm})$ & Location angle, $\lambda\left(^{\circ}\right)$ \\
\hline Straight-flute & $5.06 \times 10^{-3}$ & 69.9 \\
Helical-flute & $5.22 \times 10^{-3}$ & 73.3 \\
\hline
\end{tabular}

\subsection{Workpiece materials}

Cutting forces were analyzed under dry machining for two different workpiece materials with high strength: AZ31 Mg-alloy and Ti6Al4V alloy. All the machined specimens had dimensions of $170 \times 100 \times 12 \mathrm{~mm}$, which were rigidly clamped on the dynamometer. The workpiece was fed towards the tool so that there was a relative movement between the rotating tool and workpiece during experiments.

\subsection{Cutting tools}

The cutting tools were uncoated tungsten carbide flat-end mills with $12 \mathrm{~mm}$ diameter held in a tool holder mounted on the spindle, which had either straight or 
helical flutes. The helix angle for helical-flute tools was $30^{\circ}$. For calibration, experiments were performed with single-flute tools to simplify the experimental work. Then, four-flute ones were used to investigate the effects of tool engagement, tool geometry and workpiece material. The cutting tools are shown in Fig. 7.
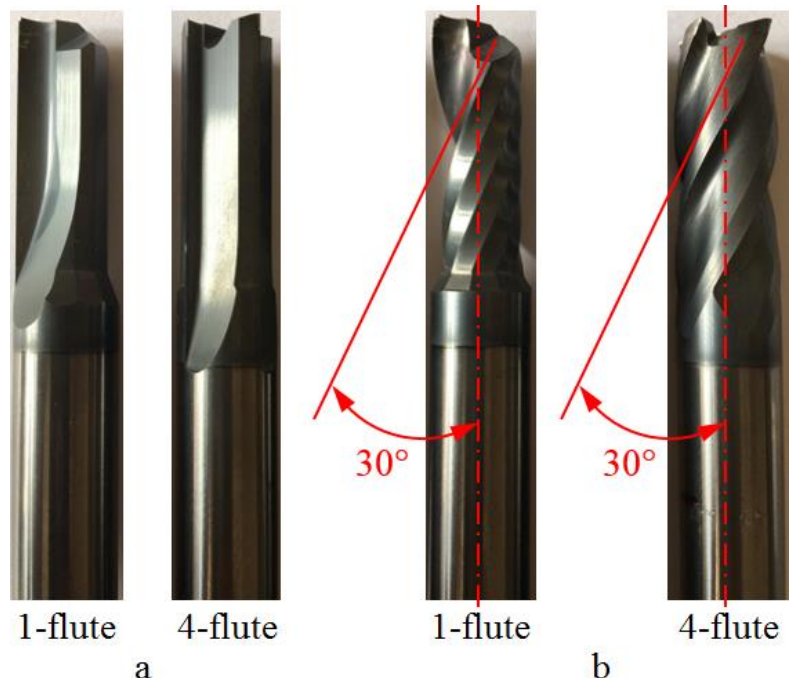

Fig. 7 Cutting tools: (a) Straight-flute, (b) Helical-flute

\subsection{Cutting conditions}

An extensive range of spindle speeds ranging from conventional to high-speed cutting was considered to obtain completely data about machinability of AZ31 Mgalloy and Ti6Al4V alloy with the straight and helical-flute end mills. To evaluate the effect of spindle speed on the force coefficients, three sets of calibration experiments were performed with three different spindle speeds of 600,1200 and $3000 \mathrm{rev} / \mathrm{min}$. For each set, four different feedrate were tested by changing the feed rate $\left(f_{z}\right)$ from 0.05 to $0.30 \mathrm{~mm} /$ flute in steps of $0.05 \mathrm{~mm} /$ flute while other parameters constant. Table 2 depicts the experimental design for calculating the force coefficients.

Table 2 Experimental design used in calibration of force coefficients

\begin{tabular}{|c|c|c|c|c|c|c|}
\hline \multirow{3}{*}{$\begin{array}{l}\text { Feed rate } \\
\text { (mm/tooth) }\end{array}$} & \multicolumn{6}{|c|}{ Forces at different feed rates for each tool-workpiece combination } \\
\hline & \multicolumn{4}{|c|}{ AZ31 Mg-alloy } & \multirow{2}{*}{\multicolumn{2}{|c|}{$\begin{array}{c}\text { Ti6Al4V alloy } \\
\text { Helical-flute end mill }\end{array}$}} \\
\hline & \multicolumn{2}{|c|}{ Straight-flute end mill } & \multicolumn{2}{|c|}{ Helical-flute end mill } & & \\
\hline 0.05 & $F_{x, 1}$ & $F_{y, 1}$ & $F_{x, 1}$ & $F_{y, 1}$ & $F_{x, 1}$ & $F_{y, 1}$ \\
\hline$\ldots$ & $\ldots$ & $\ldots$ & $\ldots$ & $\ldots$ & $\ldots$ & $\ldots$ \\
\hline$\ldots$ & $\cdots$ & $\ldots$ & $\ldots$ & $\ldots$ & $\cdots$ & $\ldots$ \\
\hline$\cdots$ & $\cdots$ & $\ldots$ & $\cdots$ & $\ldots$ & $\cdots$ & $\ldots$ \\
\hline 0.30 & $F_{x, 4}$ & $F_{y, 4}$ & $F_{x, 4}$ & $F_{y, 4}$ & $F_{x, 4}$ & $F_{y, 4}$ \\
\hline
\end{tabular}

In addition to calibration experiments, cutting experiments were performed to evaluate the effects of tool engagement, tool geometry and workpiece material on cutting forces using straight and helical-flute end mills with four flutes. It was focused on slot cutting and shoulder milling in down and up cutting configurations to study different tool engagement conditions. The tool engagement was defined with a radial depth $\left(d_{r}\right)$ of $6 \mathrm{~mm}$ for shoulder milling. The axial depth was kept constant at $2 \mathrm{~mm}$ for the entire experiments. 


\section{Results and discussion}

\subsection{Force coefficients for different tool/workpiece materials}

All the cutting force curves obtained from milling experiments have the characteristic shape presented in Fig. 8a. Unstable regions appear at the beginning and end of the curves, corresponding to entry and exit of the tool. To calibrate the force coefficients, average cutting forces were calculated from graphical data obtained in the steady region at the center of the curves for 10 spindle revolutions, as given in Fig. 8b.
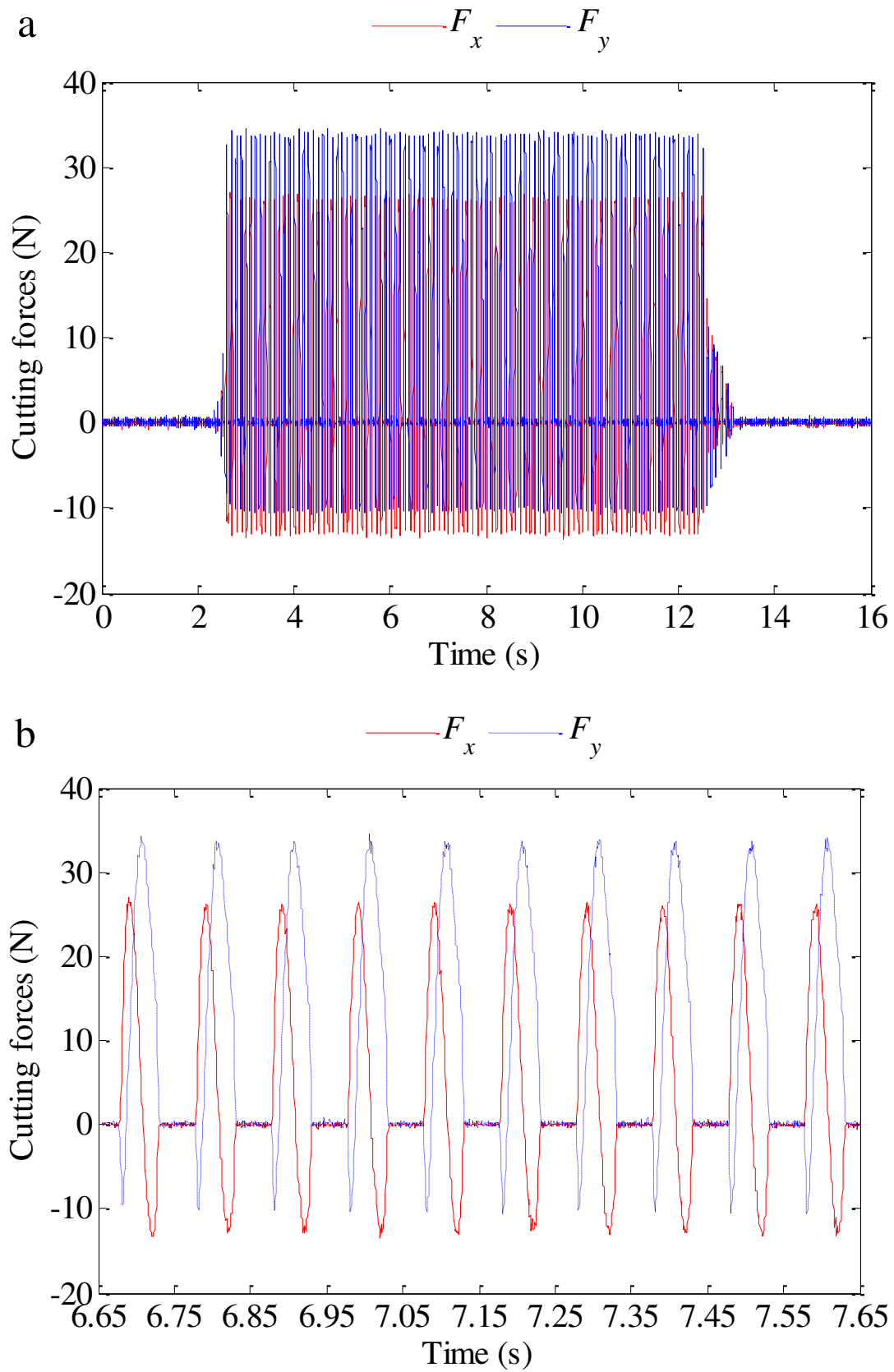

Fig. 8 Cutting forces measured in slot cutting with helical end mill: (a) All cutting force curves, (b) Sample cutting force curves in steady region

To analyze the influence of workpiece material on the force coefficients, average cutting forces in feed and transverse directions were obtained using a single-flute helical end mill for two types of workpiece materials: AZ31 Mg-alloy and Ti6Al4V 
alloy. Fig. 9 shows the relationship between feed rates and average cutting forces for carbide/AZ31 Mg-alloy pair. It can be observed that the average cutting forces change linearly with the feed per tooth. Besides, when the spindle speed increases from 600 to $3000 \mathrm{rev} / \mathrm{min}$, these linear relationships have the similar gradient.
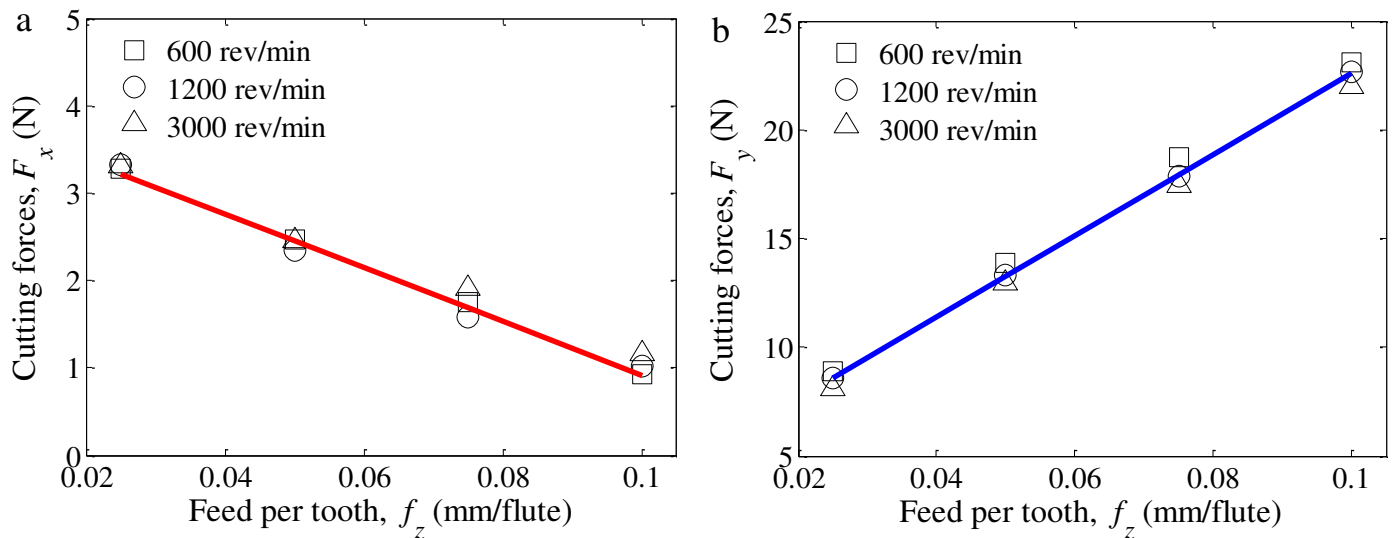

Fig. 9 Variation of average cutting forces with feed per tooth at different spindle speeds for helical-flute carbide end mill/AZ31 Mg-alloy: (a) Feed force, (b) Transverse force

The relationship between feed rates and average cutting forces for carbide/Ti6Al4V alloy pair is illustrated in Fig. 10. The average cutting forces increase linearly as the feed rate increases as reported by other researchers [22], and the gradients of the linear relationships of average cutting forces in feed and transverse directions vary with increasing spindle speed. In addition to, the magnitudes of the feed and transverse forces decrease as the spindle speed increases.
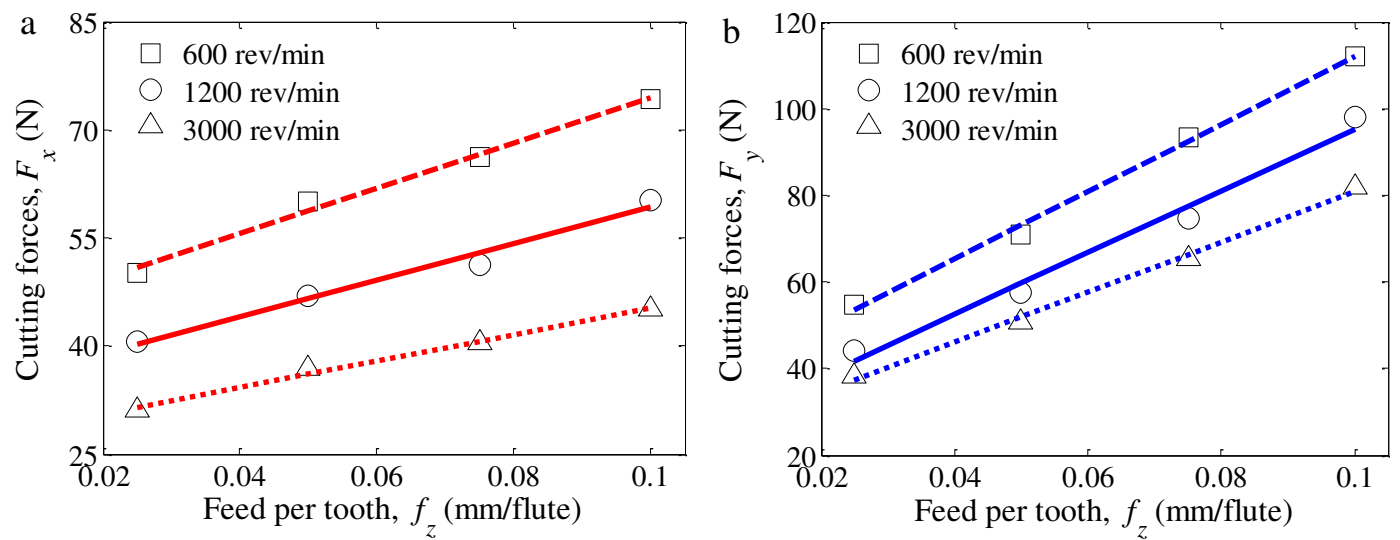

Fig. 10 Variation of average cutting forces with feed per tooth at different spindle speeds for helical-flute carbide end mill/Ti6Al4V alloy: (a) Feed force, (b) Transverse force

The cutting and edge force coefficients calibrated from the least-squares method by using the average forces for two different tool/workpiece pairs are listed in Table 3. As can be seen, the force coefficients for each tool/workpiece combination vary when cutting with the same milling parameters. The tangential and radial cutting force coefficients calculated when machining Ti6Al4V alloy are higher than those obtained in cutting AZ31 Mg-alloy. Further, it is found that when the speed is changed from 600 to $3000 \mathrm{rev} / \mathrm{min}$, the tangential and radial cutting force coefficients decrease slightly by 2.44 and $11.57 \%$ for AZ31-Mg alloy, respectively. However, there is a larger decrease of 33.71 and $71.61 \%$ in tangential and radial cutting force coefficients for Ti6Al4V alloy, respectively. These phenomena reveal that the cutting force coefficients calculated for AZ31-Mg alloy are not very sensitive to the variation of spindle speed. However, due to the variation of shearing 
behavior during cutting Ti6Al4V alloy at different spindle speeds, the cutting force coefficients depend upon the speed as seen in Fig. 11a. Also, the resulting trend is in agreement with results in Ref. [32].

It is well known that the edge force mainly results from the ploughing mechanism at the cutting edge, which is associated with the elastic-plastic property of workpiece material [33]. For AZ31 Mg-alloy, there is no significant difference in tangential and radial edge force coefficients with an increase in spindle speed. On the other hand, as can be also observed in Fig. 11b, there is a decrease of 50.48 and $59.74 \%$ in tangential and radial edge force coefficients with increasing spindle speed from 600 to $3000 \mathrm{rev} / \mathrm{min}$ for Ti6Al4V alloy, respectively. Consequently, the edge force coefficients are noticeably dependent on the properties of workpiece materials. The decrease in coefficients can be also associated with the softening of the workpiece material because of the tool-chip interface temperature increasing with spindle speed.

Table 3 Calibrated force coefficients for different tool/workpiece combinations

\begin{tabular}{lllllll}
\hline $\begin{array}{l}\text { Spindle } \\
\text { speed, } \Omega \\
(\mathrm{rev} / \mathrm{min})\end{array}$ & Tool & Workpiece & $\begin{array}{l}K_{t c} \\
\left(\mathrm{~N} / \mathrm{mm}^{2}\right)\end{array}$ & $\begin{array}{l}K_{t e} \\
(\mathrm{~N} / \mathrm{mm})\end{array}$ & $\begin{array}{l}K_{r c} \\
\left(\mathrm{~N} / \mathrm{mm}^{2}\right)\end{array}$ & $\begin{array}{l}K_{r e} \\
(\mathrm{~N} / \mathrm{mm})\end{array}$ \\
\hline 600 & & AZ31 Mg & 378.69 & 6.77 & -62.27 & 6.37 \\
1200 & $\begin{array}{c}\text { Carbide } \\
\text { helical- } \\
\text { flute end } \\
\text { mill }\end{array}$ & AZ31 Mg & 374.13 & 6.16 & -61.27 & 6.25 \\
3000 & Ti6Al4V & 1427.42 & 37.69 & 505.67 & 53.4 \\
& & Ti631 Mg & 369.67 & 5.62 & -55.81 & 6.21 \\
\hline
\end{tabular}
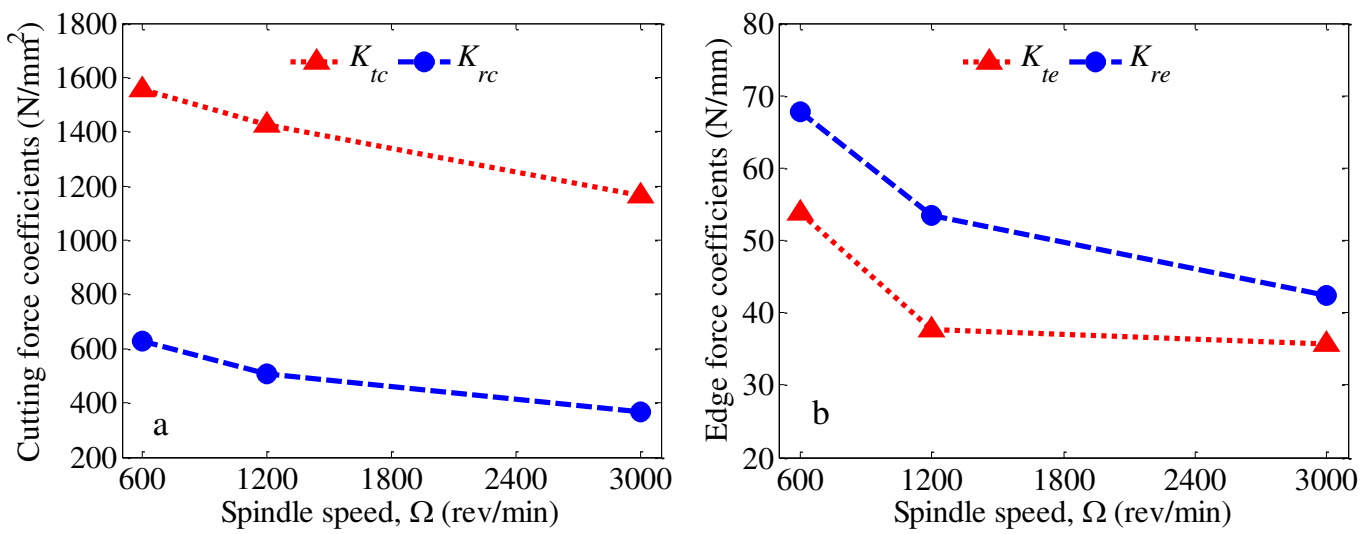

Fig. 11 Calibrated force coefficients versus spindle speeds in machining Ti6Al4V alloy: (a) Cutting force coefficients, (b) Edge force coefficients

\subsection{Force coefficients for cutting tools with different helix angle}

To identify the force coefficients for two different types of end mills with straight and helical-flute, the average cutting forces in feed and transverse directions were obtained under different spindle speeds during milling of AZ31 Mg-alloy.

The calibrated cutting and edge force coefficients are listed in Table 4. It is found that when the spindle speed is changed from 600 to $3000 \mathrm{rev} / \mathrm{min}$, the tangential cutting force coefficients decrease by 5.56 and $2.44 \%$ for straight and helical-flute 
end mills, respectively. Moreover, a comparison of radial cutting force coefficients reveals that there is a decrease of 9.85 and $11.57 \%$ with increasing spindle speed from 600 to $3000 \mathrm{rev} / \mathrm{min}$ for straight and helical-flute tools, respectively. It is evident from the above results that the magnitudes of the tangential and radial cutting force coefficients are influenced from the variation of the spindle speed.

By comparing the cutting force coefficients, it can be also seen that the cutting coefficients determined using straight end mill are higher than those obtained by the helical tool. It is noteworthy here that increasing helix angle serves to decrease the cutting force coefficients. For the tangential and radial edge force coefficients, it is observed a slight variation when using cutting tools with different helix angle or different spindle speeds. It can be concluded that the edge coefficients are independent of tool geometry.

Table 4 Cutting and edge force coefficients for straight and helical-flute end mills

\begin{tabular}{lccllll}
\hline $\begin{array}{l}\text { Spindle } \\
\text { speed, } \Omega \\
(\text { rev/min) }\end{array}$ & Tool & Workpiece & $\begin{array}{l}K_{t c} \\
\left(\mathrm{~N} / \mathrm{mm}^{2}\right)\end{array}$ & $\begin{array}{l}K_{t e} \\
(\mathrm{~N} / \mathrm{mm})\end{array}$ & $\begin{array}{l}K_{r c} \\
\left(\mathrm{~N} / \mathrm{mm}^{2}\right)\end{array}$ & $\begin{array}{l}K_{r e} \\
(\mathrm{~N} / \mathrm{mm})\end{array}$ \\
\hline 600 & Straight-flute & & 444.4 & 7.66 & 76.52 & 11.91 \\
& Helical-flute & & 378.69 & 6.77 & -62.27 & 6.37 \\
\multirow{2}{*}{1200} & Straight-flute & AZ31 Mg- & 435.71 & 6.3 & 74.87 & 7.49 \\
& Helical-flute & alloy & 374.13 & 6.16 & -61.27 & 6.25 \\
3000 & & 420.98 & 5.33 & 69.66 & 5.71 \\
& Straight-flute & & 369.67 & 5.62 & -55.81 & 6.21 \\
\hline
\end{tabular}

\subsection{Tool engagement conditions in milling}

To more carefully investigate the effect of runout on the instantaneous force profile within the envelope, the tool engagement conditions including slot cutting and shoulder milling in down and up cutting configurations were analyzed for spindle speeds ranging from conventional to high-speed cutting. The cutting tool was a four-flute helical end mill. The workpiece material was AZ31 Mg-alloy.

Fig. 12 illustrates the slot cutting configuration and the cutting force curve in feed direction with considering the tool runout obtained mechanistically at conventional spindle speed of $600 \mathrm{rev} / \mathrm{min}$ and feed rate of $0.025 \mathrm{~mm} /$ flute. It can be observed that the force curve has different peak values in time domain of one tool rotation since the runout causes each flute to experience a different chip thickness. Besides, its peaks and shape are easily identifiable. Thus, the predicted feed force was adopted to analyze cutting force curves. For four-flute $k=1,2,3,4$, the mean radial runouts $\left(e_{r k}\right)$ are $-0.008,-0.0055,0.002,-0.0025 \mathrm{~mm}$, respectively. The difference of the radius of the actual $k$ th flute with respect to the previous $(k+1)$ th one is denoted as $\delta e_{r k}=e_{r k}-e_{r k+1}$. In this case, $\delta e_{r k}$ is $-0.0025,-0.0075,0.0045,-0.0055$ $\mathrm{mm}$ for $k=1,2,3,4$, respectively. Since the absolute radius variation for a flute with respect to the previous one is smaller than the feed per tooth, i.e., $\left|\delta e_{r k}\right|<f_{z}$, every flute engages in cutting.

To reveal the presence of runout, four stages are considered as a function of the cutting tool rotation angle, corresponding to the entry and exit cut of the four flutes. Each one describes a characteristic evolution of the cutting force curve: Slot cutting 
begins when the initial flute gradually engages in cutting. A unique force peak occurs and the force decreases quickly to valley value. During the second stage, the cut geometry makes the force peak slightly different. In the third stage of slot cutting, the curve immediately begins another identical cycle but a higher force peak is produced. It is clear that this step corresponds to the entry of the high side of the tool into the workpiece. It can be also concluded that when the tool enters the cut, its low side is engaged with the workpiece. The fourth stage corresponding to the end of the cutting cycle produces a slightly higher force peak but lower force valley compared with the third stage. As a result, the magnitude of force peak becomes different at each stage since the chip load for each flute varies due to the presence of runout.
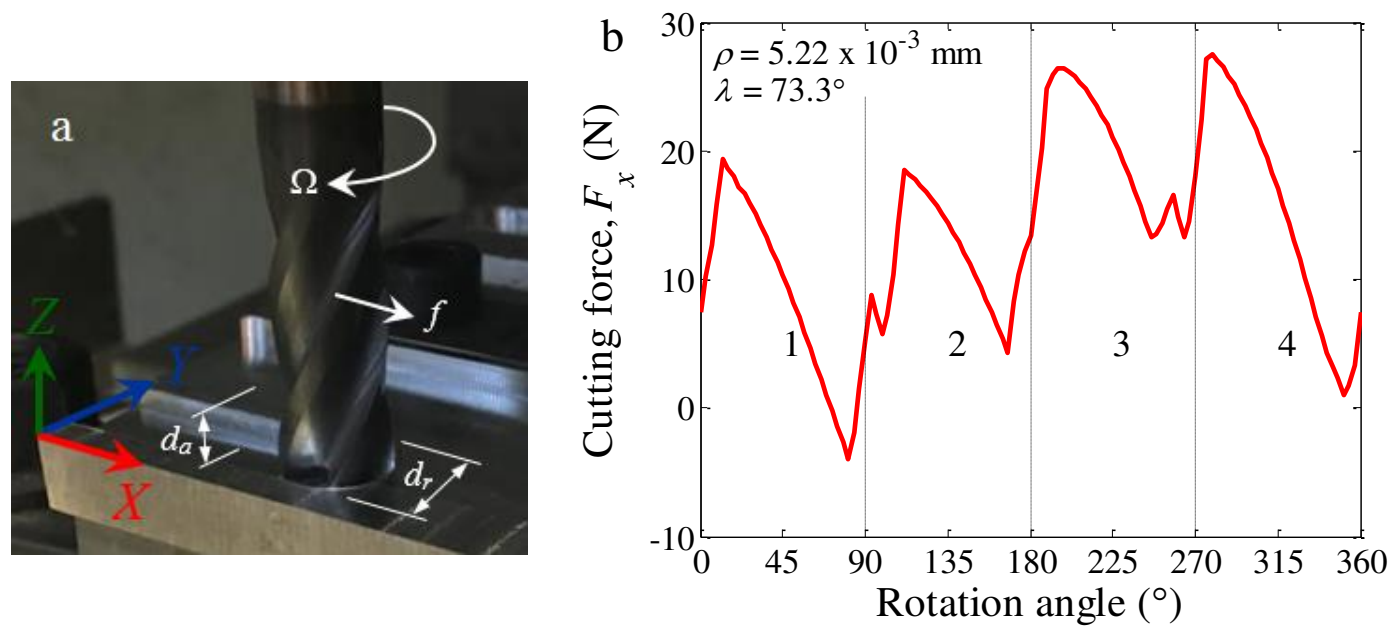

Fig. 12 Slot cutting configuration: (a) Tool engagement, (b) Theoretical cutting force curve

In case of slot cutting, the comparisons of cutting force curves obtained from the experiment and predicted from the time domain simulation are also presented in Fig. 13. It can be observed that the shape and amplitudes of the predicted cutting force profiles are in good agreement with the measured ones. Due to the existence of tool runout, the amplitudes of the measured and predicted cutting forces vary with the cutting tool rotation. The flutes on the high side of the tool are engaged with the workpiece more than those on its low side, and cause higher cutting force peaks. The differences of feed and transverse force peaks between the low and high sides of cutting tool are ratios of about 50 and $25 \%$, respectively.

For a better comparison of the results obtained from the mechanistic model, the varying amplitudes of feed and transverse force curves are analyzed, and the average of the cutting force amplitudes is obtained considering two successive revolutions, i.e., eight peaks and valleys in the curves. The peaks $\left(F_{x, P 1}, \ldots, F_{x, P 4}\right)$ and valleys $\left(F_{x, v 1}, \ldots, F_{x, v 4}\right)$ for one tool revolution are marked in Fig. 13. The average amplitude is calculated as given below

$$
F_{q}=\left[\left(F_{q, P 1}+F_{q, P 2}+\mathrm{K}+F_{q, P 8}\right)-\left(F_{q, V 1}+F_{q, V 2}+\mathrm{K}+F_{q, V 8}\right)\right] / 8 \quad(q=x, y)
$$



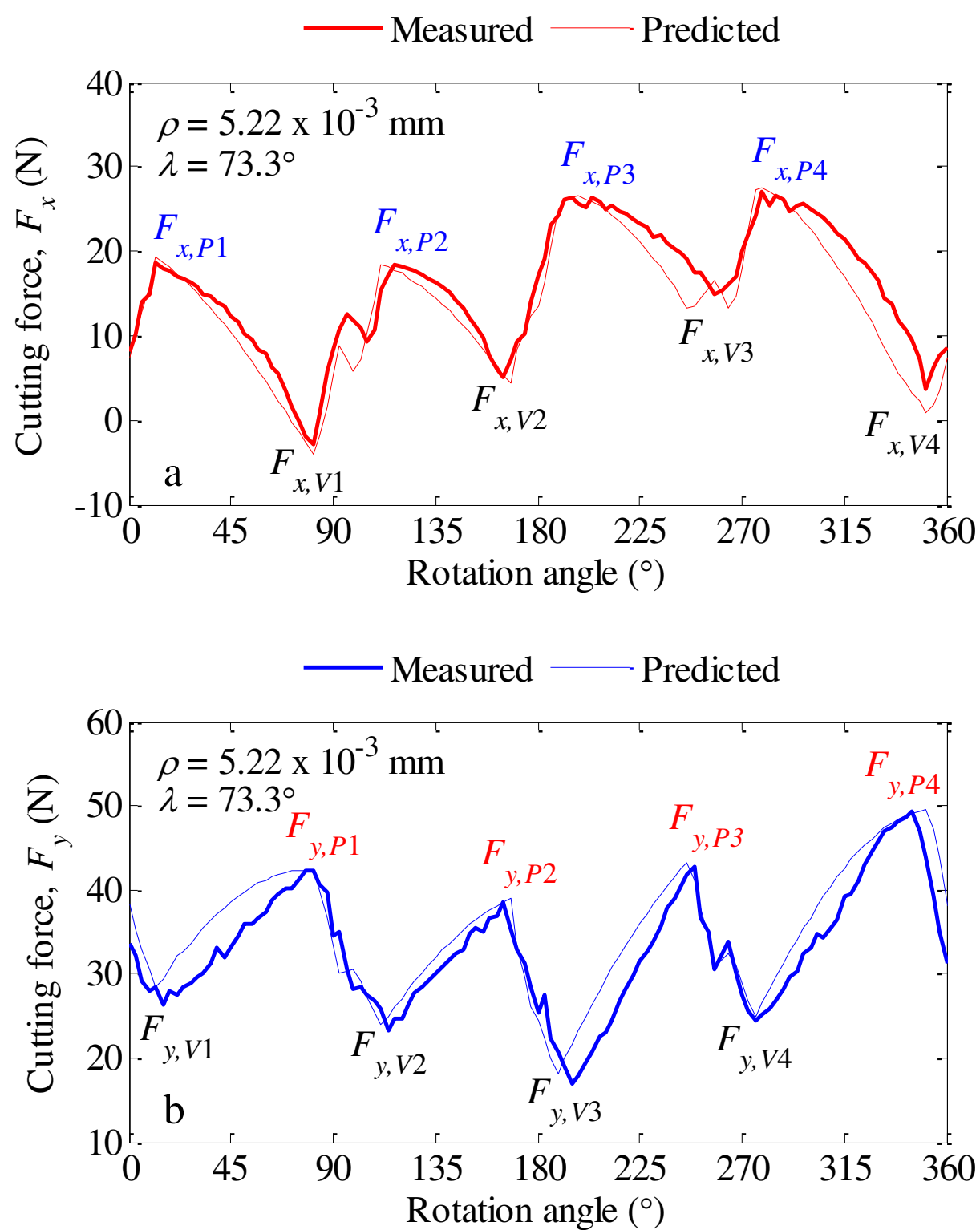

Fig. 13 Measured and predicted force curves in slot cutting: (a) Feed force, (b) Transverse force ( $\Omega=600 \mathrm{rev} / \mathrm{min}, f_{z}=0.025 \mathrm{~mm} /$ flute, $\left.d_{a}=2 \mathrm{~mm}\right)$

In this study, the mean squared errors of average amplitudes (MSE) are taken as a measure of performance of the mechanistic model, and calculated as follows

$M S E_{q}=\frac{1}{n_{s}} \sum_{s=600}^{3000}\left(\bar{F}_{q}^{M}-\bar{F}_{q}^{E}\right)^{2} \quad(q=x, y)$

where $\bar{F}_{q}^{M}$ and $\bar{F}_{q}^{E}$ are the average amplitudes of the predicted and measured signals at each spindle speed, respectively, $n_{s}$ is the number of spindle speeds $\left(n_{s}=3\right)$. The total of the mean squared errors $\left(M S E_{t o t}\right)$ for feed and transverse forces is computed as

$M S E_{t o t}=M S E_{x}+M S E_{y}$

Table 5 lists the average amplitudes along with the squared errors for the feed and transverse forces. Comparing the prediction errors, it is seen that the squared errors 
increase as the spindle speed increases in slot cutting conditions with the same axial depth and feed rate. The best correlation is achieved under low spindle speed. The force model performs well for the feed force with a mean squared error of 5.2 while a slightly higher prediction error of 9.38 is calculated for transverse force. The total of the mean squared errors is also found as 14.58. This can be attributed to considering only peripheral cutting edges of end mill in the model. In practice, the end cutting edge introduces additional cutting forces.

Table 5 Comparison of measured and predicted average force amplitudes for slot cutting ( $f_{z}=0.025 \mathrm{~mm} /$ flute, $\left.d_{a}=2 \mathrm{~mm}\right)$

\begin{tabular}{|c|c|c|c|c|c|c|c|}
\hline \multirow{2}{*}{$\begin{array}{l}\text { Spindle } \\
\text { speed, } \Omega \\
(\text { rev/min) }\end{array}$} & \multicolumn{3}{|c|}{ Feed force $(\mathrm{N})$} & \multicolumn{3}{|c|}{ Transverse force $(\mathrm{N})$} & \multirow{2}{*}{$M S E_{t o}$} \\
\hline & $\bar{F}_{x}^{M}$ & $\bar{F}_{x}^{E}$ & $\left(\bar{F}_{x}^{M}-\bar{F}_{x}^{E}\right)^{2}$ & $\bar{F}_{y}^{M}$ & $\bar{F}_{y}^{E}$ & $\left(\bar{F}_{y}^{M}-\bar{F}_{y}^{E}\right)^{2}$ & \\
\hline 600 & 19.3 & 17.3 & 4 & 19.7 & 17.5 & 4.84 & \\
\hline 1200 & 17.7 & 15.5 & 4.84 & 19.3 & 16.6 & 7.29 & \\
\hline \multirow[t]{2}{*}{3000} & 16.3 & 13.7 & 6.76 & 19.1 & 15.1 & 16 & \\
\hline & $M S E_{x}$ & & 5.2 & $M S E_{y}$ & & 9.38 & 14.58 \\
\hline
\end{tabular}

Up cutting configuration is illustrated in Fig. 14a, which corresponds to a radial immersion of $50 \%$. Fig. $14 \mathrm{~b}$ plots the predicted cutting force curve at conventional spindle speed of $600 \mathrm{rev} / \mathrm{min}$ and feed rate of $0.05 \mathrm{~mm} / \mathrm{flute}$, and four main stages are described: Up cutting begins with a chip thickness equal to zero. As the tool rotates, the cutting force gradually increases and a force peak occurs. At the end of the cut, the chip is removed, and the initial flute comes out of the workpiece. In the second stage, a slightly varying force peak and valley reveal compared with the first stage. In the third stage, the force peak is greater than those in the preceding stages. This means the entry of the high side of the tool into the workpiece. Many phenomena such as wear, vibration can occur due to increasing chip load. The fourth stage corresponds the largest force peak. It should be noted here that there are nickpoints on the curve, which correspond to the quickly entry of the flutes into the workpiece.

For the case of up cutting that is illustrated in Fig. 15, the mechanistic model gives a good description of feed and transverse forces with slight deviations in the peak and valley regions. The cutting force curves indicate a behavior close to sinusoidal, and the tool runout vary the distribution of cutting forces between each flute of the cutting tool. Also, it can be observed from the curves that the cutting process is continuous. 

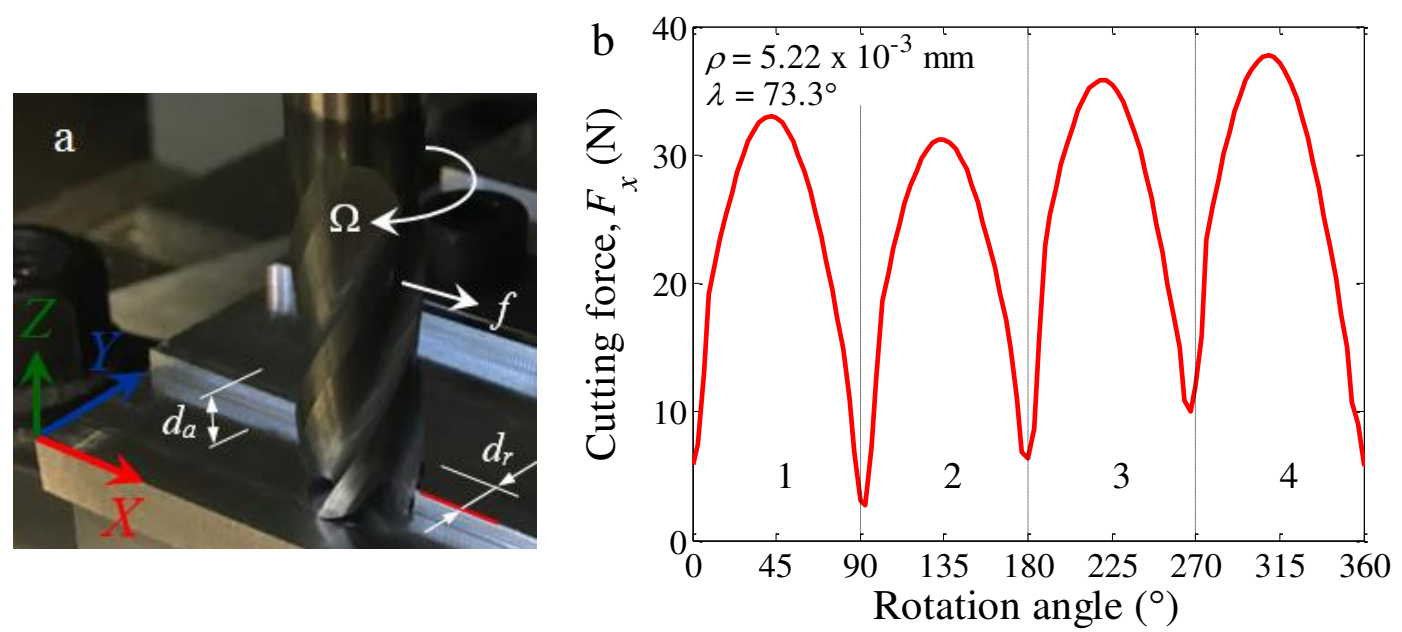

Fig. 14 Up cutting configuration: (a) Tool engagement, (b) Theoretical cutting force curve
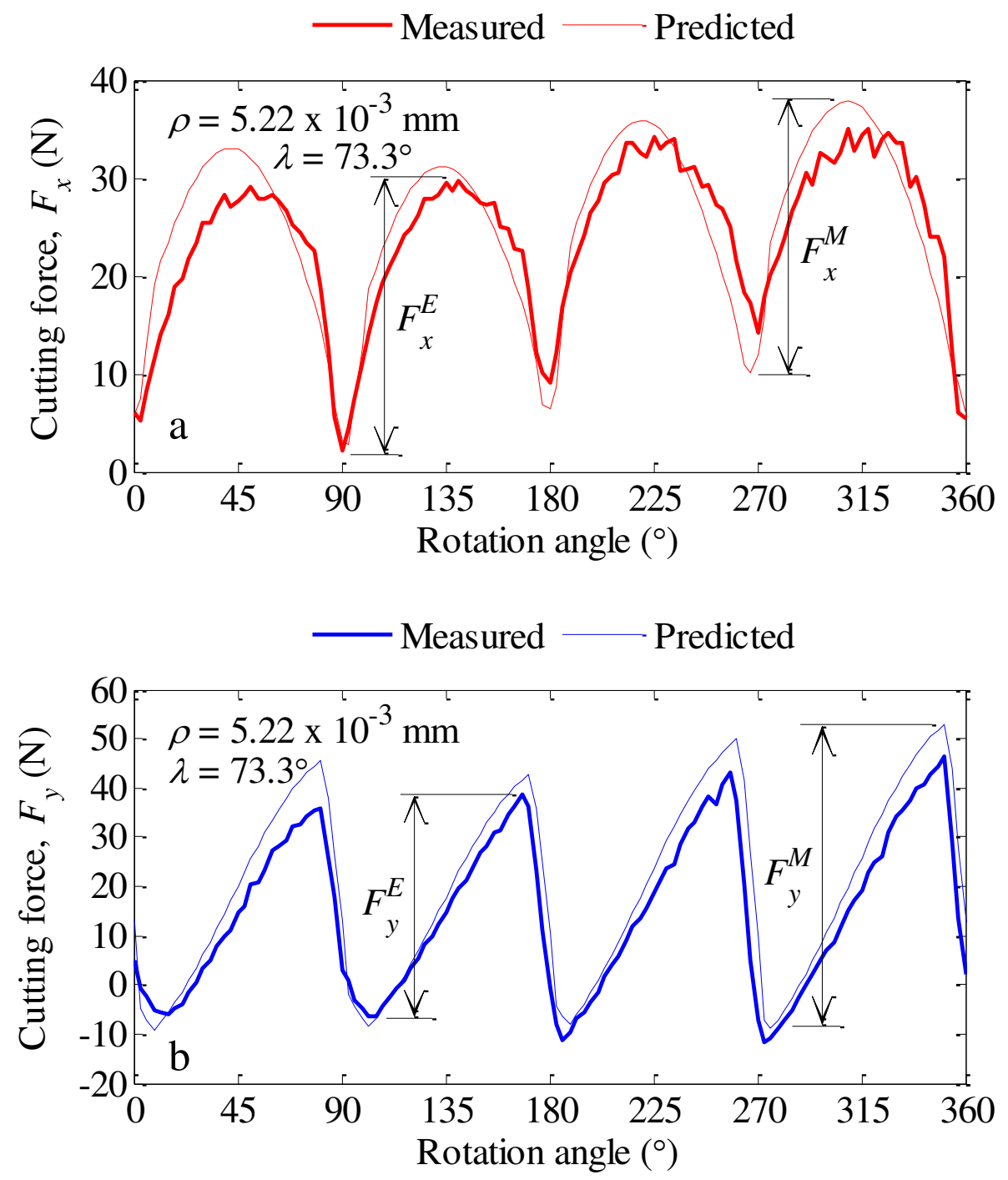

Fig. 15 Measured and predicted force curves in up cutting: (a) Feed force, (b) Transverse force ( $\Omega=600 \mathrm{rev} / \mathrm{min}, f_{z}=0.05 \mathrm{~mm} /$ flute, $d_{a}=2 \mathrm{~mm}$ )

It is interesting to compare the average amplitudes of the experimental cutting forces with those calculated mechanistically for three different cutting speeds. For up milling, Table 6 presents the average amplitudes. The mean squared errors are 
found as 17.53 and 65.35 for feed and transverse forces, respectively. The total of the mean squared errors is as high as 82.88. There is a lower accuracy for the forces derived from the mechanistic model with the rigid tool assumption at the highest spindle speed. Thus, the vibration phenomenon and flexible behavior of the tool should be considered when modelling the cutting forces for high spindle speed.

Table 6 Comparison of measured and predicted average force amplitudes for up cutting ( $f_{z}=0.05 \mathrm{~mm} /$ flute, $\left.d_{a}=2 \mathrm{~mm}\right)$

\begin{tabular}{|c|c|c|c|c|c|c|c|}
\hline \multirow{2}{*}{$\begin{array}{l}\text { Spindle } \\
\text { speed, } \Omega \\
\text { (rev/min) }\end{array}$} & \multicolumn{3}{|c|}{ Feed force $(\mathrm{N})$} & \multicolumn{3}{|c|}{ Transverse force $(\mathrm{N})$} & \multirow{2}{*}{$M S E_{t o t}$} \\
\hline & $\bar{F}_{x}^{M}$ & $\bar{F}_{x}^{E}$ & $\left(\bar{F}_{x}^{M}-\bar{F}_{x}^{E}\right)^{2}$ & $\bar{F}_{y}^{M}$ & $\bar{F}_{y}^{E}$ & $\left(\bar{F}_{y}^{M}-\bar{F}_{y}^{E}\right)^{2}$ & \\
\hline 600 & 29.4 & 25.7 & 13.69 & 56.5 & 50.4 & 37.21 & \\
\hline 1200 & 28.4 & 24.3 & 16.81 & 54.9 & 47.1 & 60.84 & \\
\hline \multirow[t]{2}{*}{3000} & 27.7 & 23 & 22.09 & 53.5 & 43.6 & 98.01 & \\
\hline & $M S E_{x}$ & & 17.53 & $M S E_{y}$ & & 65.35 & 82.88 \\
\hline
\end{tabular}

Down cutting configuration with a radial immersion of $50 \%$ and the cutting force curve predicted at spindle speed of $600 \mathrm{rev} / \mathrm{min}$ and feed rate of $0.075 \mathrm{~mm} / \mathrm{flute}$ are shown in Fig. 16. Down cutting begins with the entry of the initial flute from the straight workpiece surface. Negative magnitudes are observed in the curve because of mainly the projection of forces on the relief surface of the tool [34], which coincide with the findings of Kline and DeVor [11]. In the second stage, the tool produces a slightly lower force peak than the first stage. The third stage occurs a higher force peak than the other stages due to the entry of the high side of the tool into the workpiece. The nickpoint on the curve causes the cutting force to increase quickly in the positive direction. The fourth stage is characterized by the largest negative value, and is a critical place for the cutting force.

In the down cutting case, the experimentally observed force curves and the predicted force curves are also presented in Fig. 17. It can be observed that the model is able to predict the variations of cutting forces with rotation angle while small deviations are available in the peak and valley regions of cutting force curves. In case of four-flute, each flute path has its own profile shape and magnitude in one tool revolution since the tool runout exists. The variations in the forces are symmetric to those in up cutting.
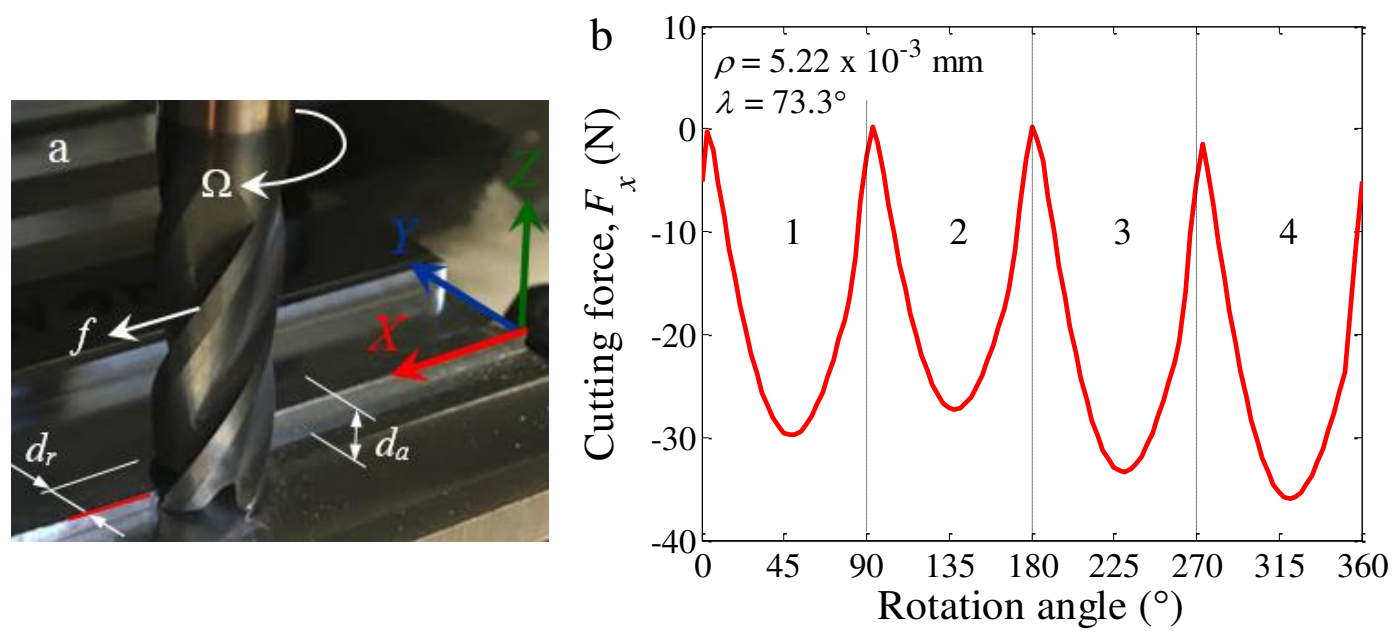

Fig. 16 Down cutting configuration: (a) Tool engagement, (b) Theoretical cutting force curve 

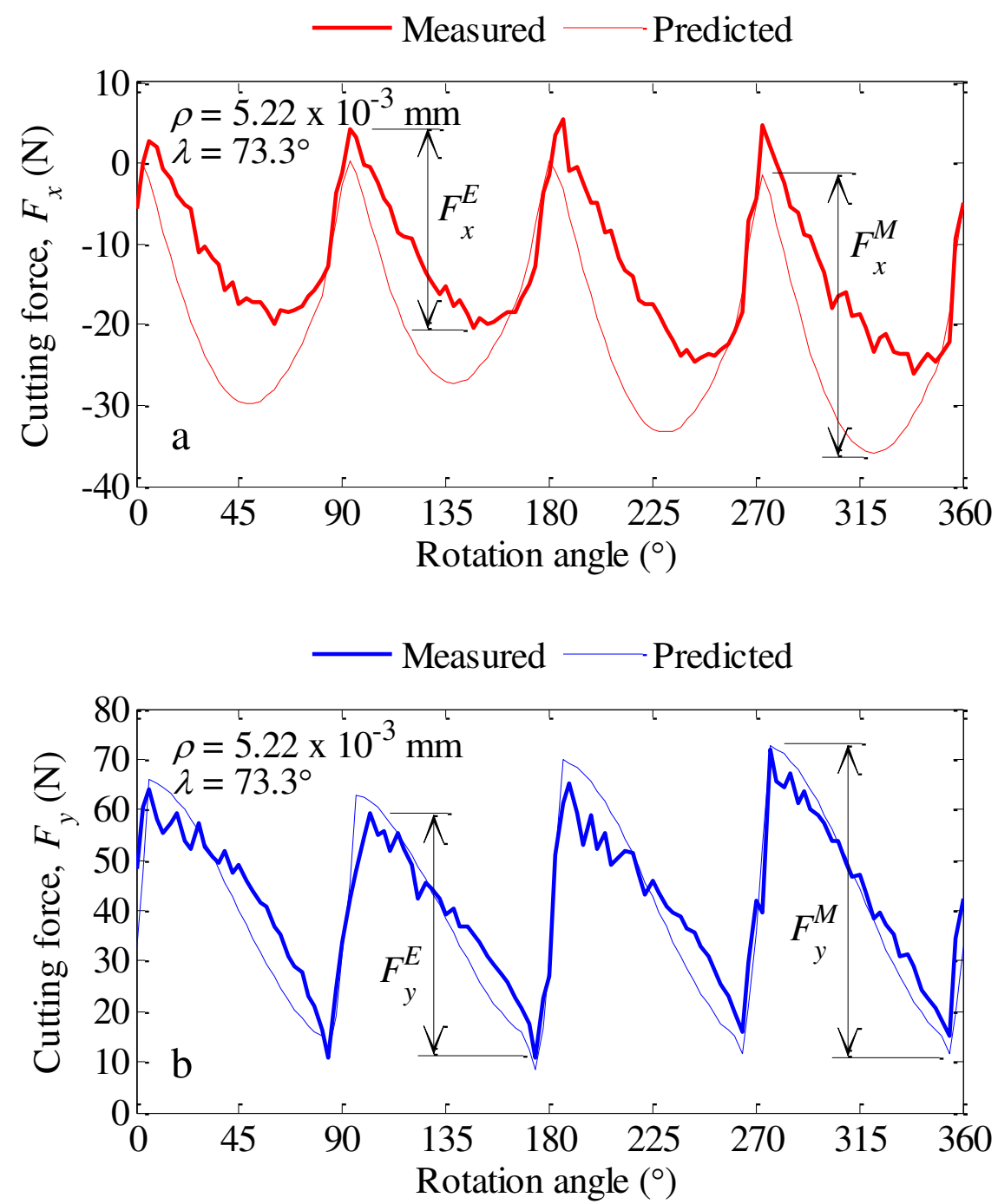

Fig. 17 Measured and predicted force curves in down cutting: (a) Feed force, (b) Transverse force ( $\Omega=600 \mathrm{rev} / \mathrm{min}, f_{z}=0.075 \mathrm{~mm} /$ flute, $d_{a}=2 \mathrm{~mm}$ )

In order to compute the deviation between the force amplitudes for down cutting configuration with runout, the experimentally measured force amplitudes and the amplitudes derived from the mechanistic force model are presented in Table 7 . The predicted feed force from the force model integrated with the chip thickness model has a mean squared error of 27.71 while the prediction error is high up to 52.59 for transverse force. Further, the total of the mean squared errors is calculated as 80.3. A better accuracy is obtained under the condition with low spindle speed.

Table 7 Comparison of measured and predicted average force amplitudes for down cutting ( $f_{z}=0.075 \mathrm{~mm} /$ flute, $d_{a}=2 \mathrm{~mm}$ )

\begin{tabular}{|c|c|c|c|c|c|c|c|}
\hline \multirow{2}{*}{$\begin{array}{l}\text { Spindle } \\
\text { speed, } \Omega \\
\text { (rev/min) }\end{array}$} & \multicolumn{3}{|c|}{ Feed force $(\mathrm{N})$} & \multicolumn{3}{|c|}{ Transverse force $(\mathrm{N})$} & \multirow{2}{*}{$M S E_{t o t}$} \\
\hline & $\bar{F}_{x}^{M}$ & $\bar{F}_{x}^{E}$ & $\left(\bar{F}_{x}^{M}-\bar{F}_{x}^{E}\right)^{2}$ & $\bar{F}_{y}^{M}$ & $\bar{F}_{y}^{E}$ & $\left(\bar{F}_{y}^{M}-\bar{F}_{y}^{E}\right)^{2}$ & \\
\hline 600 & 30.9 & 26.7 & 17.64 & 57 & 51.6 & 29.16 & \\
\hline 1200 & 29.8 & 24.6 & 27.04 & 55.5 & 48.6 & 47.61 & \\
\hline \multirow[t]{2}{*}{3000} & 29 & 22.8 & 38.44 & 53.9 & 44.9 & 81 & \\
\hline & $M S E$ & & 27.71 & $M S E_{y}$ & & 52.59 & 80.3 \\
\hline
\end{tabular}


As presented above, the accuracy of force predictions is sensitive to the tool engagement condition. The predicted cutting forces are more accurate in the slot cutting configuration for the tested cutting speed range. For the cases of up and down cutting, the feed and transverse forces are predicted with a lower accuracy.

\subsection{Influence of different tool geometries on cutting forces}

To study the influences of tool geometries on cutting forces for milling process with runout, the straight and helical end mills having four flutes were analyzed at constant feed rate of $0.1 \mathrm{~mm} /$ flute for a wide range of speeds, namely 600, 1200 and $3000 \mathrm{rev} / \mathrm{min}$. For each spindle speed, slot cutting processes were performed on AZ31 Mg-alloy.

As can be seen from the predicted force curves in Fig. 18, the straight-flute end mill gives greater force peaks than helical-flute tool at conventional spindle speed of $600 \mathrm{rev} / \mathrm{min}$. There is a sharper transition at the peak regions of feed force for end mill that has helical flutes compared with straight-flute end mill. On the other hand, a smoother transition is observed at peak regions of feed force for straight-flute end mill. For transverse forces, both straight and helical-flute end mills exhibit a sharp transition at the peak regions of each flute pass period.
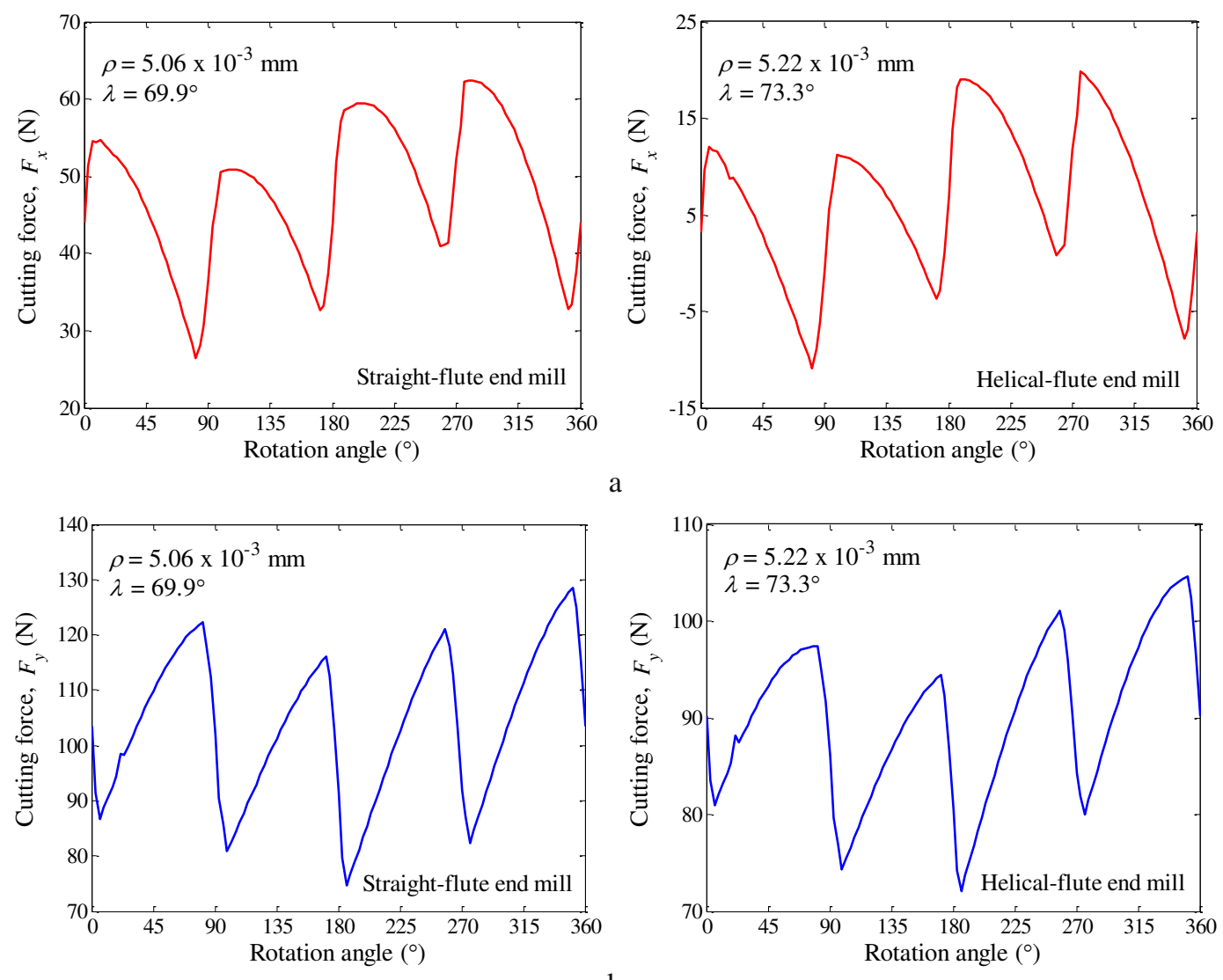

Fig. 18 Cutting force curves predicted using straight and helical-flute end mills: (a) Feed force, (b) Transverse force ( $\Omega=600 \mathrm{rev} / \mathrm{min}, f_{z}=0.1 \mathrm{~mm} / \mathrm{flute}, d_{a}=2 \mathrm{~mm}$ )

Fig. 19 shows the effects of runout on the average cutting force amplitudes for two different end mills with straight and helical flutes. It can be observed that the mechanistic model overestimates the force values consistently in the spindle speed range compared with experimental observations. This can be associated with the 
fact that tool wear is not considered in the model. The amplitudes of the measured and predicted feed and transverse forces tend to decrease as the spindle speed increases, which can be explained by the following: (i) It is generally observed that a decrease in spindle speed decreases the shear angle, and a small shear angle gives a large shear-plane area. Thus, the shear forces needed for deformation increase; (ii) At low spindle speed, the cutting forces increase due to high friction coefficient. At conventional spindle speed of $600 \mathrm{rev} / \mathrm{min}$, the helical end mill leads to a relatively small decrease of the feed force compared with the straight-flute tool. However, the measured and predicted transverse forces by the helical end mill are quite lower than those obtained using straight-flute tool at the same spindle speed. From these explanations, it is clearly seen that helical end mill greatly decreases the transverse force at low speed. For the highest spindle speed of $3000 \mathrm{rev} / \mathrm{min}$, the feed and transverse forces increase slightly with the helix angle.
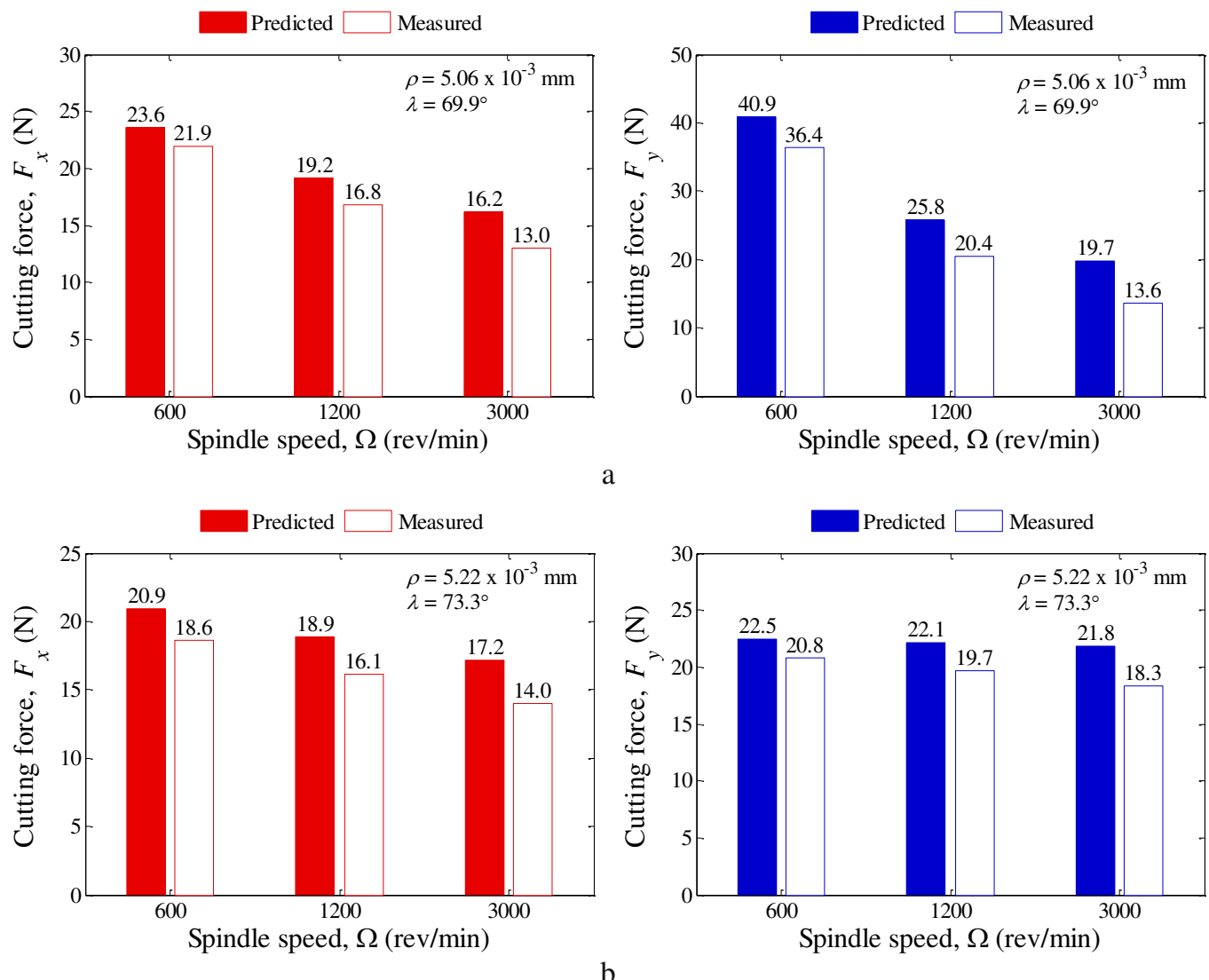

Fig. 19 Measured and predicted cutting forces using straight and helical-flute end mills: (a)

Straight-flute, (b) Helical-flute $\left(f_{z}=0.1 \mathrm{~mm} / \mathrm{flute}, d_{a}=2 \mathrm{~mm}\right)$

In addition, the prediction errors for straight and helical-flute end mills are presented in Table 8. The prediction errors in feed and transverse forces for helicalflute end mill are 7.79 and 6.97, respectively. The prediction error in feed force is identified as 6.3 in the case of straight-flute end mill, but the prediction error in transverse force is as high as 28.87. For these tools, the errors of the predicted cutting forces in feed direction are similar. However, the helical-flute end mill provides more accurate predictions for transverse force in contrast to the straightflute tool. It is obvious that for the case of helical-flute end mill, the mechanistic force model can predict the cutting forces in both feed and transverse direction with a better accuracy. 
Table 8 Predicted errors for straight and helical-flute end mills ( $f_{z}=0.1 \mathrm{~mm} /$ flute, $d_{a}=2 \mathrm{~mm}$ )

\begin{tabular}{|c|c|c|c|c|c|c|c|c|}
\hline \multirow{2}{*}{ Tool } & \multirow{2}{*}{$\begin{array}{l}\text { Spindle } \\
\text { speed, } \Omega \\
(\text { rev/min) }\end{array}$} & \multicolumn{3}{|c|}{ Feed force $(\mathrm{N})$} & \multicolumn{3}{|c|}{ Transverse force $(\mathrm{N})$} & \multirow{2}{*}{$M S E_{t o t}$} \\
\hline & & $\bar{F}_{x}^{M}$ & $\bar{F}_{x}^{E}$ & $\left(\bar{F}_{x}^{M}-\bar{F}_{x}^{E}\right)^{2}$ & $\bar{F}_{y}^{M}$ & $\bar{F}_{y}^{E}$ & $\left(\bar{F}_{y}^{M}-\bar{F}_{y}^{E}\right)^{2}$ & \\
\hline \multirow{4}{*}{$\begin{array}{l}\text { Straight- } \\
\text { flute }\end{array}$} & 600 & 23.6 & 21.9 & 2.89 & 40.9 & 36.4 & 20.25 & \\
\hline & 1200 & 19.2 & 16.8 & 5.76 & 25.8 & 20.4 & 29.16 & \\
\hline & 3000 & 16.2 & 13 & 10.24 & 19.7 & 13.6 & 37.21 & \\
\hline & & $M S E_{x}$ & & 6.3 & $M S E_{y}$ & & 28.87 & 35.17 \\
\hline \multirow{4}{*}{$\begin{array}{l}\text { Helical- } \\
\text { flute }\end{array}$} & 600 & 20.9 & 18.6 & 5.29 & 22.5 & 20.8 & 2.89 & \\
\hline & 1200 & 18.9 & 16.1 & 7.84 & 22.1 & 19.7 & 5.76 & \\
\hline & 3000 & 17.2 & 14 & 10.24 & 21.8 & 18.3 & 12.25 & \\
\hline & & $M S E_{x}$ & & 7.79 & $M S E_{y}$ & & 6.97 & 14.76 \\
\hline
\end{tabular}

\subsection{Influence of different workpiece materials on cutting forces}

To reveal the influences of workpiece materials on cutting forces for milling process with runout, two different workpiece materials were considered, AZ31 Mg and Ti6Al4V alloys. Slot cutting processes were performed at three different spindle speeds of 600,1200 and $3000 \mathrm{rev} / \mathrm{min}$ with constant feed rate of 0.05 $\mathrm{mm} /$ flute using four-flute helical end mill.

Based on the force coefficients identified at conventional spindle speed of 600 $\mathrm{rev} / \mathrm{min}$ for two different workpiece materials, the predicted cutting force curves are shown in Fig. 20. Ti6A14V alloy gives substantially greater force amplitudes than AZ31 Mg-alloy under the same cutting condition. From this result, it can be found that the machinability of Ti6Al4V alloy seems to be more critical because of the high value of amplitudes compared with AZ31 Mg-alloy. This phenomenon can be very important in high-speed cutting owing to the dynamic effects appearing with the increase of spindle speed.

Fig. 21 presents the trends of the measured and predicted cutting force amplitudes changing with spindle speed in machining of AZ31 Mg-alloy and Ti6Al4V alloy. It can be observed that the amplitudes of the measured and predicted cutting force components in feed and transverse directions for Ti6Al4V alloy are higher at conventional speed, and show a decrease with increasing spindle speed. Also, AZ31 $\mathrm{Mg}$-alloy results in slightly varying amplitudes with spindle speed. In the case of slot cutting of Ti6Al4V alloy, the measured and predicted feed and transverse forces are considerably higher than those predicted in slot milling of AZ31 Mg-alloy over the spindle speed range. 

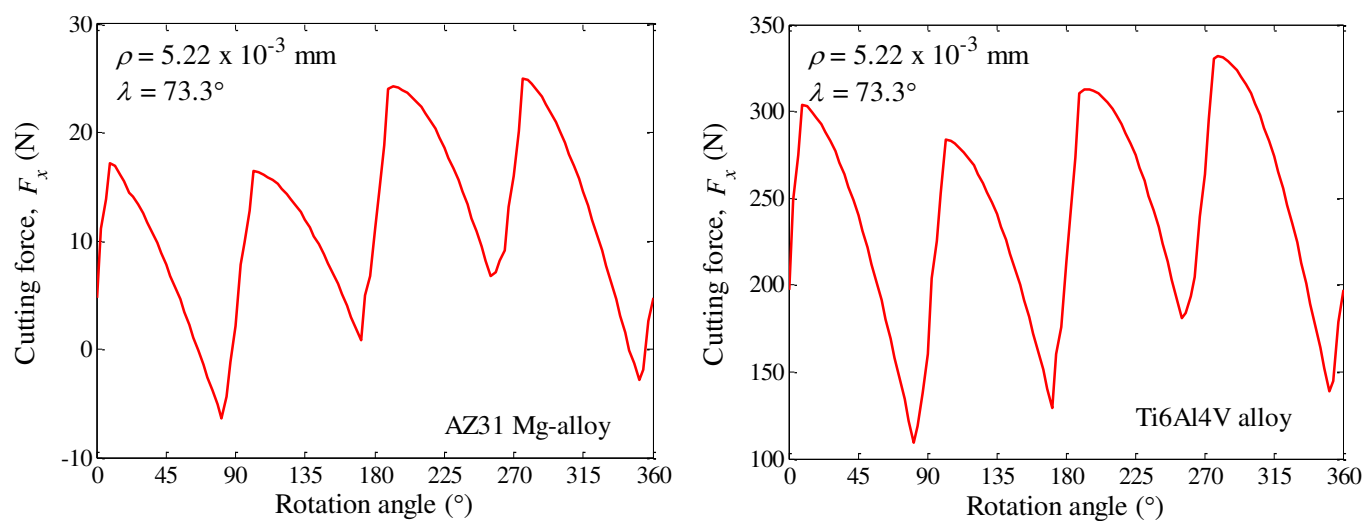

a
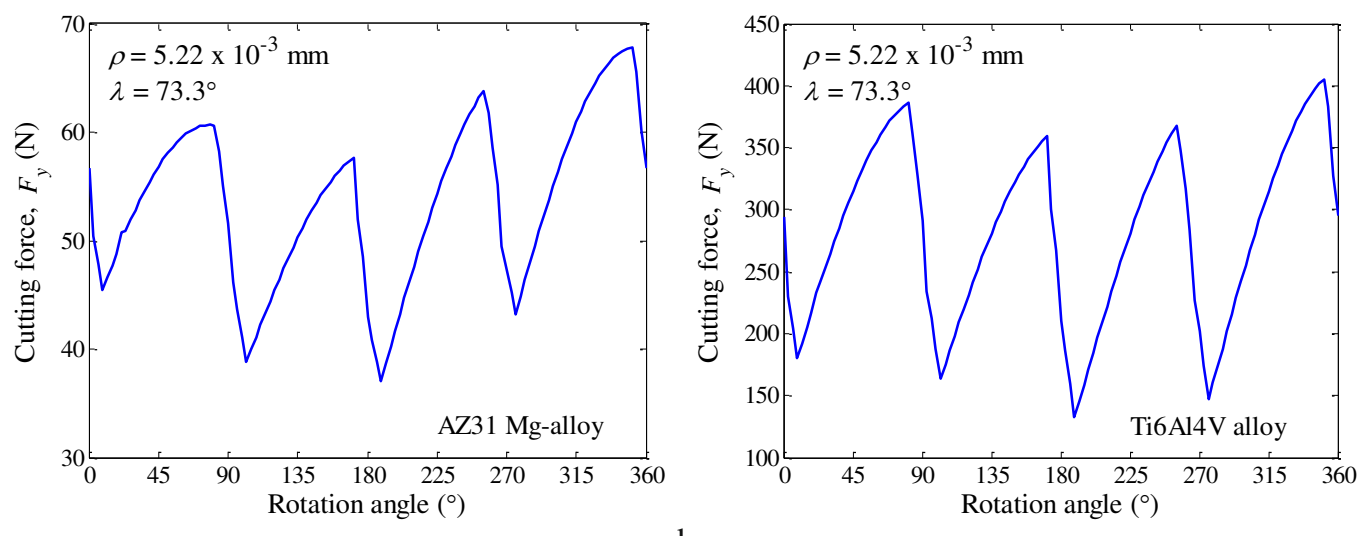

b

Fig. 20 Cutting force curves predicted for AZ31 Mg and Ti6Al4V alloys: (a) Feed force, (b) Transverse force ( $\Omega=600 \mathrm{rev} / \mathrm{min}, f_{z}=0.05 \mathrm{~mm} /$ flute, $d_{a}=2 \mathrm{~mm}$ )
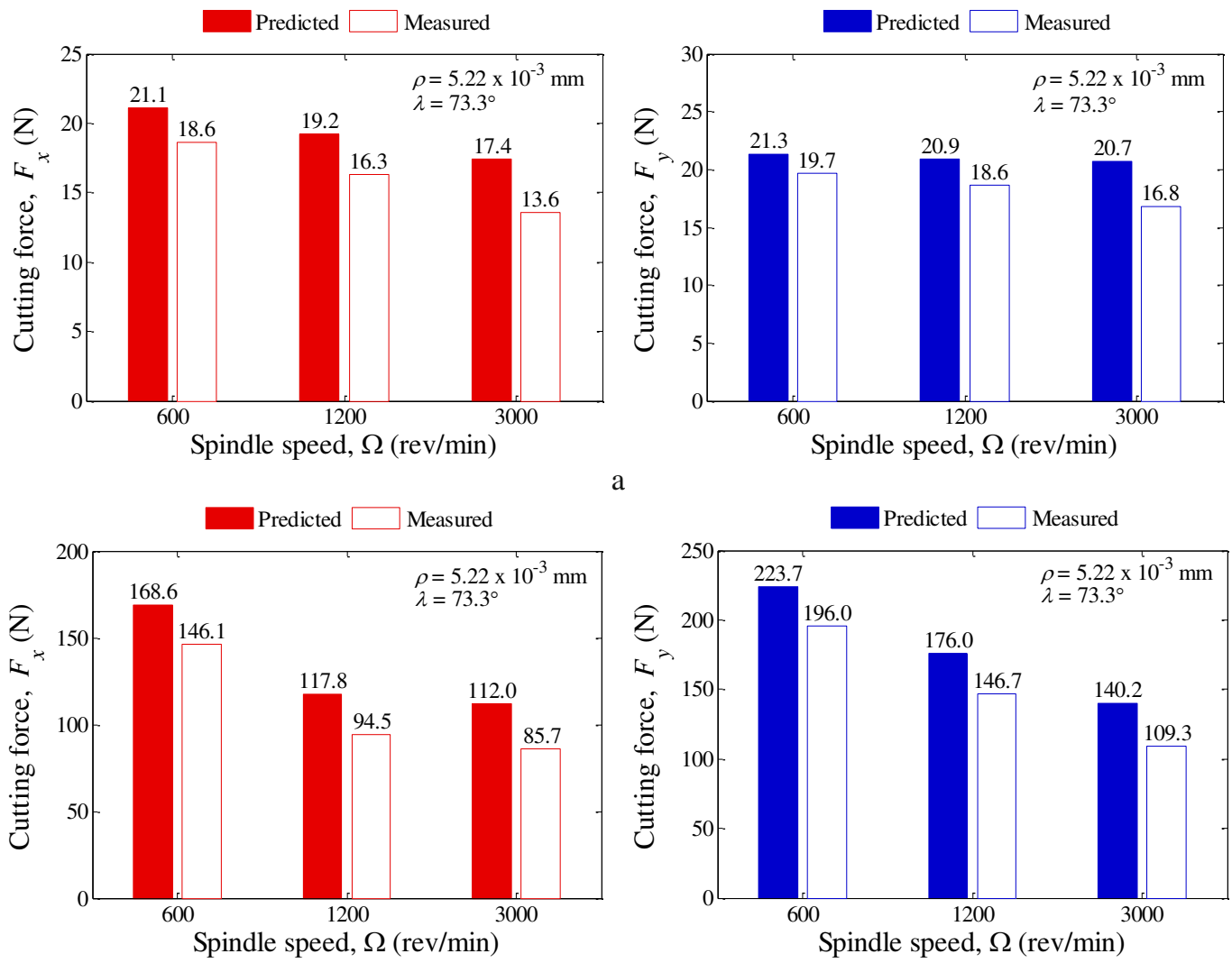

b

Fig. 21 Measured and predicted cutting forces for AZ31 Mg and Ti6Al4V alloys: (a) AZ31 Mgalloy, (b) Ti6Al4V alloy $\left(f_{z}=0.05 \mathrm{~mm} /\right.$ flute, $d_{a}=2 \mathrm{~mm}$ ) 
Table 9 gives the prediction errors for AZ31 Mg and Ti6Al4V alloys. As can be seen from the table, the prediction accuracy of feed and transverse forces is dependent on the workpiece material. In machining of AZ31 Mg-alloy, the prediction errors in feed and transverse forces are 9.7 and 7.69 , respectively. The prediction error in feed force is identified as 580.28 in machining of Ti6Al4V alloy; moreover, the error in transverse force prediction is as high as 860.2. That is, Ti6Al4V alloy results in more accurate predictions for feed force in contrast to the transverse force. Finally, it appears that for machining case of AZ31 Mg-alloy, the mechanistic model including the effect of runout can predict the cutting forces with a better accuracy.

Table 9 Predicted errors for AZ31 Mg and Ti6Al4V alloys $\left(f_{z}=0.05 \mathrm{~mm} / \mathrm{flute}, d_{a}=2 \mathrm{~mm}\right)$

\begin{tabular}{|c|c|c|c|c|c|c|c|c|}
\hline \multirow{2}{*}{ Workpiece } & \multirow{2}{*}{$\begin{array}{l}\text { Spindle } \\
\text { speed, } \Omega \\
\text { (rev/min) }\end{array}$} & \multicolumn{2}{|c|}{ Feed force $(\mathrm{N})$} & \multicolumn{4}{|c|}{ Transverse force $(\mathrm{N})$} & \multirow{2}{*}{$M S E_{\text {tot }}$} \\
\hline & & $\bar{F}_{x}^{M}$ & $\bar{F}_{x}^{E}$ & $\left(\bar{F}_{x}^{M}-\bar{F}_{x}^{E}\right)^{2}$ & $\bar{F}_{y}^{M}$ & $\bar{F}_{y}^{E}$ & $\left(\bar{F}_{y}^{M}-\bar{F}_{y}^{E}\right)^{2}$ & \\
\hline \multirow[t]{4}{*}{$\begin{array}{l}\text { AZ31 } \\
\text { Mg-alloy }\end{array}$} & 600 & 21.1 & 18.6 & 6.25 & 21.3 & 19.7 & 2.56 & \\
\hline & 1200 & 19.2 & 16.3 & 8.41 & 20.9 & 18.6 & 5.29 & \\
\hline & 3000 & 17.4 & 13.6 & 14.44 & 20.7 & 16.8 & 15.21 & \\
\hline & & $M S E_{x}$ & & 9.7 & $M S E_{y}$ & & 7.69 & 17.39 \\
\hline \multirow[t]{4}{*}{$\begin{array}{l}\text { Ti6Al4V } \\
\text { alloy }\end{array}$} & 600 & 168.6 & 146.1 & 506.25 & 223.7 & 196 & 767.29 & \\
\hline & 1200 & 117.8 & 94.5 & 542.89 & 176 & 146.7 & 858.49 & \\
\hline & 3000 & 112 & 85.7 & 691.69 & 140.2 & 109.3 & 954.81 & \\
\hline & & $M S E_{x}$ & & 580.28 & $M S E_{y}$ & & 860.2 & 1440.4 \\
\hline
\end{tabular}

\section{Conclusions}

In this research, a systematic study to model the cutting forces for flat-end milling with tool runout has been presented by considering the effects of tool geometry, workpiece material and process parameters such as tool engagement and cutting direction for a wide range of spindle speeds ranging from conventional to highspeed milling. A mechanistic force model which predicts the cutting forces based on the undeformed chip thickness calculated from the trochoidal flute trajectories was used, and the average force method and linear regression model were considered to evaluate the force coefficients. Based on this research, the following observations are drawn:

1. The force coefficients can be determined as constant values with respect to the variation of spindle speed to improve the accuracy of the predicted forces for a particular tool-workpiece couple. Since the shearing mechanism changes with increasing spindle speed, there is a tendency to decrease especially in cutting force coefficients. Also, the edge coefficients are independent to the tool geometry.

2. The conventional spindle speed produces larger cutting forces than high speed, and the amplitudes of the predicted cutting forces under conventional spindle speed agree well with the measured values. However, in the case of high-speed end milling, the predicted cutting forces deviate from those 
obtained experimentally since dynamic phenomena appear with increasing spindle speed. Accordingly, the rigid tool assumption drastically limits the predictive capacity of the model to the conventional spindle speed.

3. The accuracy of the predicted cutting forces highly depends on the workpiece material. For spindle speeds ranging from conventional to highspeed machining, AZ31 Mg-alloy provides higher cutting force prediction accuracy than Ti6Al4V alloy. Also, the helix angle has a significant effect on the cutting forces, particularly the transverse force at conventional speed.

4. For a rigid end milling process, the tool runout causes a considerable variation in the cutting force curve over the rotation of a multi-flute tool. Besides, the flutes on the high side of cutting tool with runout encounter larger force peaks than those on the other side. Thus, the runout effect should be taken into account to analyze the cutting forces in end milling.

Author contribution All the authors have equally involved in preparing the manuscript.

Data Availability The data and materials supporting the results of this study are included in the article.

\section{Declarations}

Ethics approval Not applicable.

Consent to participate Not applicable.

Consent for publication Not applicable.

Competing interests The authors declare no competing interests

\section{References}

[1] Li HZ, Li XP (2005) A numerical study of the effects of cutter runout on milling process geometry based on true tooth trajectory. Int J Adv Manuf Technol 25:435-443

[2] Schmitz TL, Couey J, Marsh E, Mauntler N, Hughes D (2007) Runout effects in milling: Surface finish, surface location error, and stability. Int J Mach Tools Manuf 47:841-851

[3] Aydın M, Uçar M, Cengiz A, Kurt M (2015) Identification of static surface form errors from cutting force distribution in flat-end milling processes. J Braz Soc Mech Sci 37:1001-1013

[4] Islam MN, Lee HU, Cho DW (2008) Prediction and analysis of size tolerances achievable in peripheral end milling. Int J Adv Manuf Technol 39:129-141

[5] Ehman KF, Kapoor SG, DeVor RE, Lazoglu I (1997) Machining process modeling: A review. J Manuf Sci Eng 119:655-663

[6] Armarego EJA, Deshpande NP (1993) Force prediction models and CAD/CAM software for helical tooth milling processes. I. Basic approach and cutting analysis. Int J Prod Res 31(8):1991-2009

[7] Li XP, Li HZ (2004) Theoretical modelling of cutting forces in helical end milling with cutter runout. Int J Mech Sci 46:1399-1414

[8] Wang JJ, Liang SY (1996) Chip load kinematics in milling with radial cutter runout. J Eng Ind 118(1):111-116

[9] Mackerle J (2003) Finite element analysis and simulation of machining: an addendum: a bibliography (1996-2002). Int J Mach Tools Manuf 43:103-114 
[10] Altintas Y · (2000) Modeling approaches and software for predicting the performance of milling operations at MAL-UBC. Mach Sci Technol 4(3), 445-478

[11] Kline WA, DeVor RE (1983) The effect of runout on cutting geometry and forces in end milling. Int J Mach Tool Des Res 23(2/3):123-140

[12] Yun WS, Cho DW (2000) An Improved Method for the Determination of 3D Cutting Force Coefficients and Runout Parameters in End Milling. Int J Adv Manuf Technol 16:851-858

[13] Wan M, Zhang WH (2006) Calculations of chip thickness and cutting forces in flexible end milling. Int J Adv Manuf Technol 29:637-647

[14] Montgomery D, Altintas Y (1991) Mechanism of cutting force and surface generation in dynamic milling. J Eng Ind 113:160-168

[15] Wojciechowski S (2015) The estimation of cutting forces and specific force coefficients during finishing ball end milling of inclined surfaces. Int J Mach Tools Manuf 89:110-123.

[16] Aydın M, Uçar M, Cengiz A, Kurt M, Barkın B (2014) A methodology for cutting force prediction in side milling. Mater Manuf Process 29:1429-1435.

[17] Wan M, Zhang WH, Qin GH, Wang ZP (2008) Consistency study on three cutting force modelling methods for peripheral milling. Proc Inst Mech Eng B J Eng Manuf 222(6):665676

[18] Dikshit MK, Puri AB, Maity A (2017) Analysis of cutting force coefficients in high-speed ball end milling at varying rotational speeds. Mach Sci Technol 21(3):416-435

[19] Budak E, Altıntaş Y, Armerago EJA (1996) Prediction of milling force coefficients from orthogonal cutting data. J Manuf Sci Eng 118:216-224

[20] Aydın M, Köklü U (2017) Identification and modeling of cutting forces in ball-end milling based on two different finite element models with Arbitrary Lagrangian Eulerian technique. Int J Adv Manuf Technol 92:1465-1480

[21] Aydın M, Köklü U (2020) Analysis of flat-end milling forces considering chip formation process in high-speed cutting of Ti6Al4V titanium alloy. Simul Model Pract Th 100:102039

[22] Rubeo MA, Schmitz TL (2016) Mechanistic force model coefficients: A comparison of linear regression and nonlinear optimization Precis Eng 45:311-321

[23] Wan M, Zhang WH, Tan G, Qin GH (2007) New algorithm for calibration of instantaneous cutting-force coefficients and radial run-out parameters in flat end milling. Proc Inst Mech Eng B J Eng Manuf 221(6):1007-1019

[24] Wan M, Zhang WH, Dang JW, Yang Y (2010) A novel cutting force modelling method for cylindrical end mill. Appl Math Model 34 (2010) 823-836

[25] Budak E (2006) Analytical models for high performance milling. Part I: cutting forces, structural deformations and tolerance integrity. Int J Mach Tools Manuf 46(12-13):1478-1488

[26] Adem KAM, Fales R, El-Gizawy AS (2015) Identification of cutting force coefficients for the linear and nonlinear force models in end milling process using average forces and optimization technique methods. Int J Adv Manuf Technol 79:1671-1687

[27] Tlusty J (2000) Manufacturing processes and equipment. Prentice Hall, Upper Saddle River, NJ

[28] Dikshit MK, Puri AB, Maity A (2017) Analysis of rotational speed variations on cutting force coefficients in high-speed ball end milling. J Braz. Soc. Mech. Sci. Eng. (2017) 39:3529-3539

[29] Kumanchik LM, Schmitz TL (2007) Improved analytical chip thickness model for milling. Precis Eng 31:317-324

[30] Sutherland JW, DeVor RE (1986) An improved method for cutting force and surface error prediction in flexible end milling systems. J Eng Ind, 108:269-279

[31] Yalcin C (2009) Milling cutter software architecture for force and surface finish modeling. PhD Dissertation, University of New Hampshire

[32] Grossi N, Sallese L, Scippa A, Campatelli G. (2015) Speed-varying cutting force coefficient identification in milling. Precis Eng 42:321-334 
[33] Wan M, Ma YC, Feng J, WH Zhang (2016) Study of static and dynamic ploughing mechanisms by establishing generalized model with static milling forces. Int J Mech Sci 114:120-131

[34] Maurel-Pantel A, Fontaine M, Michel G, Thibaud S, Gelin JC (2013) Experimental investigations from conventional to high speed milling on a 304-L stainless steel. Int J Adv Manuf Technol 69:2191-2213 